\title{
Synthetic Microbiomes on the Rise-Application in Deciphering the Role of Microbes in Host Health and Disease
}

\author{
Silvia Bolsega, André Bleich (D) and Marijana Basic*(D) \\ Institute for Laboratory Animal Science, Hannover Medical School, 30625 Hannover, Germany; \\ bolsega.silvia@mh-hannover.de (S.B.); bleich.andre@mh-hannover.de (A.B.) \\ * Correspondence: basic.marijana@mh-hannover.de
}

Citation: Bolsega, S.; Bleich, A.;

Basic, M. Synthetic Microbiomes on the Rise-Application in Deciphering the Role of Microbes in Host Health and Disease. Nutrients 2021, 13, 4173. https://doi.org/10.3390/nu13114173

Academic Editors: Peter M. Abuja and Eva Untersmayr

Received: 30 September 2021 Accepted: 17 November 2021 Published: 21 November 2021

Publisher's Note: MDPI stays neutral with regard to jurisdictional claims in published maps and institutional affiliations.

Copyright: (c) 2021 by the authors. Licensee MDPI, Basel, Switzerland. This article is an open access article distributed under the terms and conditions of the Creative Commons Attribution (CC BY) license (https:// creativecommons.org/licenses/by/ $4.0 /)$.

\begin{abstract}
The intestinal microbiota conveys significant benefits to host physiology. Although multiple chronic disorders have been associated with alterations in the intestinal microbiota composition and function, it is still unclear whether these changes are a cause or a consequence. Hence, to translate microbiome research into clinical application, it is necessary to provide a proof of causality of host-microbiota interactions. This is hampered by the complexity of the gut microbiome and many confounding factors. The application of gnotobiotic animal models associated with synthetic communities allows us to address the cause-effect relationship between the host and intestinal microbiota by reducing the microbiome complexity on a manageable level. In recent years, diverse bacterial communities were assembled to analyze the role of microorganisms in infectious, inflammatory, and metabolic diseases. In this review, we outline their application and features. Furthermore, we discuss the differences between human-derived and model-specific communities. Lastly, we highlight the necessity of generating novel synthetic communities to unravel the microbial role associated with specific health outcomes and disease phenotypes. This understanding is essential for the development of novel non-invasive targeted therapeutic strategies to control and modulate intestinal microbiota in health and disease.
\end{abstract}

Keywords: synthetic communities; minimal microbiota; intestinal microbiota; host-microbe interactions; gnotobiotic animal models; microbiome; intestinal diseases; metabolism

\section{Introduction}

The intestine is inhabited by a complex community of microbes that are engaged in a symbiotic/mutualistic interaction with the host. This community participates in many relevant physiological processes for the host such as the maturation of the mucosal immune system and the microbial breakdown of essential food components [1]. Contrarily, shifts in bacterial composition have been associated with the development of multiple human disorders including infectious, inflammatory, metabolic, and autoimmune diseases, as well as with the outcome of colorectal cancer [2-7]. However, it is still unclear whether these compositional perturbations are a cause or rather a consequence of a disease. Microbiome-wide association studies performed over the last decade provided a catalog of microbial species that could be used as biomarkers to distinguish healthy population from patients with severe diseases [8,9]. Nevertheless, although the presence of particular microbial genus or species was associated with a certain disease state, studies demonstrating their causative role are still mainly lacking. Thus, to translate microbial correlation into causation, we need to generate models in which functional and mechanistic studies can be addressed. One valuable tool to assess the causal role of microbes in host health and disease is the usage of gnotobiotic animal models [10-12]. The word "gnotobiotic" is derived from the Greek "gnotos" (meaning well-known) and "bios" (meaning life). It describes organisms with a fully known microbial status including germ-free animals, which are devoid of all living microorganisms, and animals associated with known microbial species. Although studies 
in germ-free models are necessary to confirm microbiota-induced phenotype, studies in models with defined microbial composition are particularly appealing, as here, beneficial or detrimental effects of individual microbes or microbial communities can be assessed. Thus, gnotobiotic models represent a unique tool to reduce the complexity of intestinal microbiome sufficiently to perform mechanistic studies. Furthermore, models with this type of microbial standardization can reduce experimental variability and increase experimental reproducibility. The colonization of germ-free animals with minimal microbiomes provides an attractive approach to assess the causality of disease-associated microbial alterations. Hence, it is essential to extend the use and assemble novel synthetic communities ("syncoms"). Syncoms can be employed as both "top-down" and "bottom-up" methodological strategies in microbiome research (Figure 1). In a "top-down" approach, syncoms can be assembled based on the gut community data acquired through the analysis of omics data (e.g., taxonomic diversity, bacterial abundance, dominating taxa, metabolic activity). With this approach, syncoms can be used to recapitulate microbiome signatures observed in microbiota-dependent phenotypes to assess their functionality and causality. Based on these signatures, health- or disease-associated taxa can be isolated, and a novel simplified community can be assembled. The "bottom-up" strategy relies on combining individual microorganisms that are previously cultured and well characterized (e.g., their taxonomic affiliation, ecological niches, individual metabolic profiles, or interactions). Based on a study-specific hypothesis, individual microbial species with particular features can be combined to assemble study-specific syncoms [13]. However, the prerequisite for the extended usage and assembling of novel syncoms is the isolation and cultivation of host-specific microbial taxa and their availability in public strain collections [14-16].

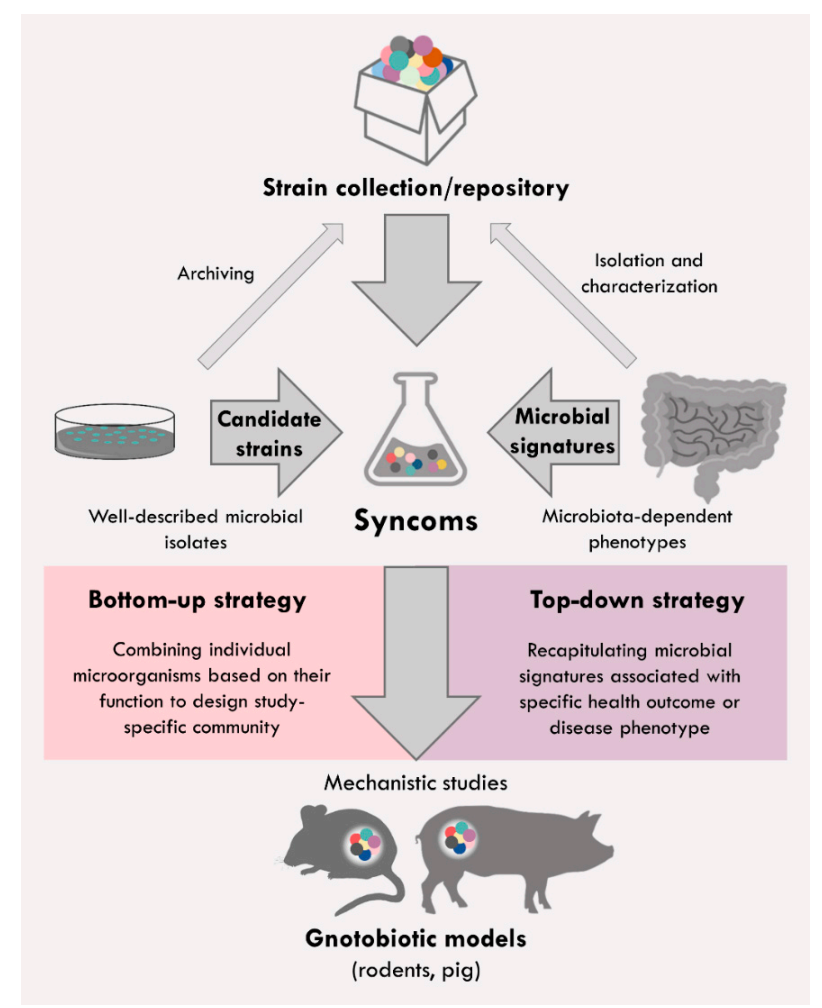

Figure 1. Methodological strategies to assemble syncoms. In a "bottom-up" approach, individual well-described microbial candidates based on their function are combined to assemble study-specific syncoms. In a "top-down" approach, syncoms are assembled to recapitulate observed microbial signatures associated with specific health outcomes and disease phenotypes. The prerequisite for the assemblage of novel communities is the isolation, characterization, and archiving of microbial strains in public repositories. Generated syncoms can be introduced in germ-free animal models such as germ-free rodents and pigs to perform mechanistic or proof-of-concept studies. 
In this review, we provide an overview of existing synthetic gut microbiomes/communities and their application in microbiome research to decipher mechanisms underlying hostmicrobiota interactions in health and disease. In particular, we focus on in vivo models that integrate a supplementary level of complexity and knowledge, i.e., the host responses, in contrast to a recent review by Mabwi et al. that is focused on ex vivo culturomics of synthetic gut microbiota and mathematical modeling [17].

\section{Syncoms Representing Simplified Intestinal Microbiome}

The first attempt to create a synthetic community was undertaken to standardize hygienic conditions in rodent breeding facilities. Russel W. Schaedler performed this pioneer work and established a defined mixture of six cultivable bacterial strains isolated from Nelson Collins Swiss mice [18]. The selection of the Schaedler flora members was based on their cultivability in the laboratory setting [19]. This first syncom included two strains of Lactobacilli, one strain of anaerobic Streptococcus Group N, two strains of Bacteroides, and a coliform strain [18]. The disadvantage of this minimal community was the presence of facultative anaerobes, which outgrew microbial contaminants [20]. Thus, this minimal consortium was modified in 1978 by Roger P. Orcutt to enable better hygiene monitoring. In this mixture, facultative anaerobes were replaced with obligate anaerobes representing the major microbiota constituents of the mouse gut [21]. This refined microbiota was called altered Schaedler flora (ASF) and included eight anaerobic bacterial strains Clostridium sp. ASF356, Lactobacillus acidophilus ASF360, Lactobacillus murinus ASF361, Mucispirillum schaedleri ASF457, Eubacterium plexicaudatum ASF492, Pseudoflavonifractor sp. ASF500, Schaedlerella arabinosiphila ASF502, and Parabacteroides goldsteinii ASF519 [22]. By inoculating germfree mice with these bacterial species, a few of the anatomical abnormalities caused by housing under germ-free conditions can be normalized such as cecum size and fecal consistency [18]. However, compared to a complex endogenous microbiota, the ASF syncom is not able to exert colonization resistance and does not recapitulate all major functions of the enteric microbiota. Several studies have shown that introduced microbes including viruses and bacteria can successfully colonize the gut of ASF-associated mice [23-25]. This implies that these mice are also highly susceptible to contamination by environmental bacteria and fungi [26], especially if aseptic condition in animal handling by scientists and animal caretakers is not strictly kept. Even though the ASF is widely used in biomedical research, individual bacterial species are not available in public strain collections, complicating the study-based modification of the consortium. In 2020, a novel defined syncom was created by combining some of the ASF members with representative bacteria isolated from specific-opportunistic-pathogen-free C57BL/6J mice including four species obtained from the public repository "German Collection of Microorganisms and Cell Cultures" [27]. This minimal community was named GM15 and includes 15 gut-derived bacterial species (Lactobacillus johnsonii MD006, Lactobacillus murinus MD040, Limosilactobacillus reuteri MD207, Parabacteroides goldsteinii MD072, Bacteroides acidifaciens MD185, three Lachnospiraceae sp.strains MD308, MD335, and MD329, Bacteroides caecimuris MD237, Schaedlerella arabinosiphila (ASF502) MD300, Clostridium sp. (ASF356) MD294, Enterocloster clostridioformis YL32, Clostridium cocleatum I50, Escherichia coli Mt1B1, and Anaerotruncus colihominis JM4-15) [27]. The GM15 community is described as an innovative gnotobiotic model to standardize laboratory rodent husbandry that increases the reproducibility and robustness of preclinical studies. The rationale behind GM15 assembly was the stable colonization of germ-free mice, comparability with indigenous mouse gut microbiota at the functional level, and simplified monitoring. Oligo-Mouse-Microbiota $12\left(\mathrm{OMM}^{12}\right)$ also termed stable defined moderately diverse microbiota (sDMDMm2) is another example of the mouse-derived minimal bacterial microbiome [28,29]. This synthetic bacterial community was developed to decipher the contribution of individual strains to host-microbe and microbe-microbe interactions. $\mathrm{OMM}^{12}$ shows typical characteristics of a complex microbiota, as it provides partial colonization resistance against enteric pathogens [29]. It comprises twelve bacterial isolates assigned to five major phyla (Bacteroidetes, Firmicutes, 
Verrucomicrobia, Proteobacteria, and Actinobacteria). The selection of bacterial strains was guided by phylogenetic diversity and public availability. All twelve $\mathrm{OMM}^{12}$ members (Akkermansia muciniphila YL44, Bacteroides caecimuris I48, Muribaculum intestinale YL27, Turicimonas muris YL45, Bifidobacterium longum subsp. animalis YL2, Enterococcus faecalis KB1, Acutalibacter muris KB18, Enterocloster clostridioformis YL32, Blautia coccoides YL58, Flavonifractor plautii YL31, Limosilactobacillus reuteri I49, and Clostridium innocuum I46) are included in public strain collection of "German Collection of Microorganisms and Cell Cultures". Furthermore, $\mathrm{OMM}^{12}$ characterizes the long-term stability and high reproducibility accomplished in different animal laboratories $[29,30]$. In a recent study by Streidl et al., this syncom was used for studies addressing host-microbiome metabolic cross-talk. OMM ${ }^{12}$ was modulated with Extibacter muris, which is a gut bacterium that metabolizes cholic acid, a form of primary bile acid, into secondary bile acid deoxycholic acid. Secondary bile acids, deoxycholic and lithocholic acid, as well as their taurine conjugates were detected solely in mice co-colonized with E. muris. Moreover, this model was able to show that the production of secondary bile acids influenced proteomes in the liver [31]. The production of microbial metabolites such as secondary bile acids can affect inflammatory and metabolic processes. Due to the added microbial function, this extended model consortium could be used to investigate the pathophysiological impact of secondary bile acids on the host. Altogether, $\mathrm{OMM}^{12}$ represents an attractive model consortium for targeted mechanistic studies, as it allows flexible experimental design. An overview of the available rodent-derived syncoms and their application in microbiome research is given in Table 1.

Table 1. Overview of the application of rodent-derived syncoms in microbiome research.

\begin{tabular}{|c|c|c|c|}
\hline Syncom & Composition & Application/Research Question & Ref. \\
\hline \multirow{4}{*}{ ASF } & \multirow{2}{*}{$\begin{array}{l}\text { Clostridium sp. ASF356, L. acidophilus ASF360, L. } \\
\text { murinus ASF361, M. schaedleri ASF457, E. plexicaudatum } \\
\text { ASF492, Pseudoflavonifractor sp. ASF500, S. } \\
\text { arabinosiphila ASF502, P. goldsteinii ASF519 }\end{array}$} & $\begin{array}{c}\text { Standardization of laboratory rodent } \\
\text { husbandry }\end{array}$ & [21] \\
\hline & & $\begin{array}{l}\text { Impact of host-mediated factors on chronic } \\
\text { inflammation }\end{array}$ & [32] \\
\hline & + E. coli strains & \multirow{2}{*}{$\begin{array}{l}\text { Impact of microbiota on intestinal } \\
\text { inflammation }\end{array}$} & [33] \\
\hline & $\begin{array}{c}\text { +Murine norovirus } \\
+ \text { Segmented filamentous bacteria }\end{array}$ & & {$[23,34]$} \\
\hline & $\begin{array}{l}\text { L. acidophilus ASF360, L. murinus ASF361, M. schaedleri } \\
\text { ASF457, P. goldsteinii ASF519, B. fibrisolvens }\end{array}$ & $\begin{array}{l}\text { Diet-related microbial protection against } \\
\text { colorectal cancer }\end{array}$ & [35] \\
\hline GM15 & $\begin{array}{c}\text { L. johnsonii, L. murinus, L. reuteri, } \\
\text { P. goldsteinii, B. acidifaciens, } 3 \times \text { Lachnospiraceae sp. } \\
\text { strains, B. caecimuris, S. arabinosiphila ASF502, } \\
\text { Clostridium sp. ASF356, E clostridioformis YL32, C. } \\
\text { cocleatum, E. coli, A. colihominis }\end{array}$ & $\begin{array}{c}\text { Standardization of laboratory rodent } \\
\text { husbandry }\end{array}$ & [27] \\
\hline \multirow{6}{*}{$\mathrm{OMM}^{12}$} & $\begin{array}{c}\text { A. muciniphila YL44, B. caecimuris I48, M. intestinale } \\
\text { YL27, T. muris YL45, B. longum subsp. animalis YL2, E. } \\
\text { faecalis KB1, A. muris KB18, E. clostridioformis YL32, B. } \\
\text { coccoides YL58, F. plautii YL31, L. reuteri I49, C. } \\
\text { innocuum I46 }\end{array}$ & $\begin{array}{l}\text { Mechanisms of colonization resistance } \\
\text { against enteric pathogens }\end{array}$ & [29] \\
\hline & + E. muris & $\begin{array}{l}\text { Host-microbe metabolic cross-talk and bile } \\
\text { metabolism }\end{array}$ & [31] \\
\hline & $+C$. scindens & $\begin{array}{l}\text { Mechanisms of colonization resistance } \\
\text { against } C \text {. difficile }\end{array}$ & [36] \\
\hline & $\begin{array}{c}\text { +Murine norovirus } \\
+ \text { +Segmented filamentous bacteria }\end{array}$ & $\begin{array}{l}\text { Impact of microbiota on intestinal } \\
\text { inflammation }\end{array}$ & [23] \\
\hline & $+A$. finegoldii & $\begin{array}{l}\text { Host-microbe metabolic cross-talk and diet } \\
\text { impact on inflammation }\end{array}$ & [37] \\
\hline & + M. schaedleri & $\begin{array}{c}\text { Impact of microbiota on Salmonella-induced } \\
\text { intestinal inflammation }\end{array}$ & [38] \\
\hline
\end{tabular}

Creating human-like conditions in the animal intestine by colonizing germ-free organisms with bacteria isolated from complex human stool samples supports the targeted 
investigation of important biochemical processes and host-microbe interactions in the digestive tract of people. Humanized animal models mimic more closely the interactions in human intestine and can increase our understanding of microbiota-associated phenotypes of human disorders [39]. Thus, syncoms based on human-derived strains have also been developed (Table 2). The simplified human intestinal microbiota (SIHUMI) consortium is composed of seven bacterial species belonging to the phyla Firmicutes (Anaerostipes caccae L1-92, Blautia producta 2396, Clostridium ramosum 113-I, Lactobacillus plantarum Lp 39), Bacteroidetes (Bacteroides thetaiotaomicron E50), Actinobacteria (Bifidobacterium longum NCC2705), and Proteobacteria (Escherichia coli K-12 MG1655) [40]. These bacterial species were selected based on their high abundance in the human gut, fermentative abilities, and the ability to form a stable community in the rodent intestine [40]. Colonization with SIHUMI resulted in increased fecal concentration of short-chain fatty acids (SCFA). As the fecal butyrate concentration was low, the butyrate-producing bacterium Clostridium butyricum Rowett was added to the SIHUMI consortium to form the extended SIHUMIx microbiota. SIHUMIx syncom recapitulated metabolic features of conventional animals such as SCFA production, as well as mucus, $B$-aspartylglycine, and bilirubin degradation [40]. The simplified intestinal microbiota consortium (SIM) is another human-derived syncom composed of ten microbial isolates (Eubacterium hallii L2-7, Eubacterium rectale A1-86, Bifidobacterium adolescentis L2-32, Collinsella aerofaciens VPI 1003, Desulfovibrio piger VPI 11112, Roseburia inulinivorans A2-194, Ruminococcus bromii L2-63, Bacteroides thetaiotaomicron VPI 5482, Prevotella copri DSM18205, and Akkermansia muciniphila Muc) [41]. This syncom was generated to clarify how bacteria-diet interactions contribute to metabolic disorders. The selection criteria for SIM consortium assembly were dominated abundance in the human gut, a fully sequenced genome available in the public database, and well-characterized metabolic features including complementing properties to metabolize dietary components. Thus, SIM community recapitulates many functions of the complex human microbiota and may facilitate our understanding of how the microbes interact with macronutrients to affect host metabolism in a diet-specific manner [41]. In a similar line, Rezzonico et al. established a humanized gnotobiotic mouse model by choosing ten dominating and easy-to-grow bacteria from stool samples of adult humans (Bacteroides thetaiotaomicron E50, Bacteroides vulgatus DSM1447, Bifidobacterium longum NCC2705, Blautia hansenii VPI C7-24, Clostridium scindens 19, Collinsella aerofaciens DSM3979, Escherichia coli HS, Eubacterium ventriosum VPI 1013B, Faecalibacterium prausnitzii A2-165, and Lactobacillus rhamnosus NCC4007). The advantage for the use of this consortium in studies is the availability of the microbial members in public bacterial collections and the completely sequenced genome. Metabolic characterization of this syncom showed that the microbial composition affects hosts metabolic profiles, which may play a substantial role in physiological processes and disease development in humans [42]. Other synthetic human bacterial communities to be mentioned here have been developed to investigate inter-bacterial communication and interactions. Welch et al. used a defined 15member model consortium comprised of phylogenetically diverse and sequenced human gut bacterial strains to explore the spatial organization of the gut microbiota [43]. Imaging analyses of this syncom revealed that luminal and mucosal proximal colon compartments are not sharply stratified but should rather be seen as an incompletely mixed bioreactor [44]. Denou et al. investigated the interactions between three human commensals: Escherichia coli K-12, Lactobacillus johnsonii NCC533, and Bifidobacterium longum NCC2705 [45]. This syncom was used as a model community to study cooperation and competition interactions in the mammalian gut. The introduction of additional microbes such as E. coli Nissle strain in this model system allowed studying how different gut species coexist or are eliminated due to the provided colonization resistance. Furthermore, by studying this simple interacting bacterial population, factors governing the microbial ecology and dynamic within the gastrointestinal tract can be determined. Similar human-derived syncom comprised of three prominent Bacteroides species (Bacteroides ovatus ATCC 8483, B. vulgatus ATCC 8482 , and $B$. thetaiotaomicron VPI 5482) was assembled to analyze cooperation interactions within the Bacteroidales, which is the dominant Gram-negative bacterial taxa of the human 
intestine [46]. This study provided evidence of a distinct form of cooperativity within the Bacteroidales taxa that represent an example of naturally evolved cooperative interactions between the microbes [46]. The ability of microbes to utilize the waste products of another species is well-known example of cooperation interactions [47]. However, in this study, a cross-feeding enzyme system in the gut symbiont B. ovatus was discovered, which digests inulin at a benefit to another species, as these enzymes are unnecessary for its use of inulin. By the extracellular digestion of inulin, B. ovatus feeds other gut species, which in return provide benefits to $B$. ovatus. These data support the hypothesis that these strong eco-evolutionary interactions within the microbiota are essential for the ecological stability and functioning of intestinal communities [46].

Table 2. Overview of the application of human-derived syncoms in microbiome research.

\begin{tabular}{|c|c|c|c|}
\hline Syncom & Composition & Application/Research Question & Ref. \\
\hline SIHUMI & $\begin{array}{c}\text { A. caccae, B. producta, C. ramosum, } \\
\text { L. plantarum, B. Theta }{ }^{1} \text {, B. longum, E. coli } \mathrm{K}-12\end{array}$ & Host-bacteria interactions & [40] \\
\hline \multirow{4}{*}{ SIHUMIx } & \multirow[t]{2}{*}{$\begin{array}{l}\text { A. caccae, B. producta, C. ramosum, L. plantarum, B. } \\
\text { theta }^{1} \text {, B. longum, E. coli } \mathrm{K}-12, \text { C. butyricum }\end{array}$} & $\begin{array}{l}\text { Host-microbe metabolic cross-talk and } \\
\text { impact of microbiota on intestinal } \\
\text { inflammation }\end{array}$ & [40] \\
\hline & & Diet-related microbial effect on obesity & {$[48,49]$} \\
\hline & \multirow[b]{2}{*}{+ A. muciniphila } & $\begin{array}{l}\text { Impact of microbiota on intestinal } \\
\text { inflammation }\end{array}$ & [50] \\
\hline & & $\begin{array}{c}\text { Impact of microbiota on } \\
\text { Salmonella-induced intestinal } \\
\text { inflammation }\end{array}$ & [51] \\
\hline \multirow[t]{2}{*}{ SIHUMI } & $\begin{array}{l}\text { E. faecalis, } R \text {. gnavus, F. prausnitzii, L. plantarum, B. } \\
\text { vulgatus, E. coli, B. longum subsp. longum }\end{array}$ & \multirow{2}{*}{$\begin{array}{l}\text { Impact of IBD-related microbiota on } \\
\text { intestinal inflammation }\end{array}$} & [52] \\
\hline & -E. faecalis & & [53] \\
\hline SIM & $\begin{array}{c}\text { E. hallii, E. rectale, B. adolescentis, C. aerofaciens, D. } \\
\text { piger, R. inulinivorans, R. bromii, B. theta, P. copri, } \\
\text { A. muciniphila }\end{array}$ & $\begin{array}{l}\text { Microbe-diet interaction and impact on } \\
\text { metabolism }\end{array}$ & [41] \\
\hline \multirow[t]{7}{*}{ MET-1 } & $\begin{array}{l}4 \times \text { Bifidobacterium species, C. aerofaciens, } B \text {. } \\
\text { ovatus, P. distasonis, } 2 \times \text { Lactobacillus species, } S \text {. } \\
\text { mitis, F. prausnitzii, C. cocleatum, A. intestine, } \\
\text { Blautia sp., } 2 \times \text { Dorea species, L. pectinoshiza, } 2 \times \\
\text { Roseburia species, } 4 \times \text { Ruminococcus species, } 7 \times \\
\text { Eubacterium species, E. coli, Raoultella sp. }\end{array}$ & $\begin{array}{l}\text { Host-microbe interaction and } \\
\text { protection against systemic disease }\end{array}$ & [54] \\
\hline & $\begin{array}{c}\text { B. theta }{ }^{1} \text {, B. vulgatus, B. longum, B. hansenii, C. } \\
\text { scindens, C. aerofaciens, E. coli, E. ventriosum, F. } \\
\text { prausnitzii, L. rhamnosus }\end{array}$ & $\begin{array}{l}\text { Host-microbe metabolic cross-talk and } \\
\text { impact on metabolism }\end{array}$ & [42] \\
\hline & E. coli K-12, L. johnsonii, B. longum, E. coli Nissle & Microbial cooperation and competition & [45] \\
\hline & B. ovatus, B. vulgatos, B. theta ${ }^{1}$ & Microbial cooperation & [46] \\
\hline & $\begin{array}{l}\text { B. longum subsp. infantis, B. breve, B. bifidum, B. } \\
\text { dentium }\end{array}$ & $\begin{array}{l}\text { Host-microbe interaction and microbial } \\
\text { impact on nervous system }\end{array}$ & [55] \\
\hline & R. gnavus, B. theta, C. hathewayi, C. orbiscindens & $\begin{array}{l}\text { Mechanisms of colonization resistance } \\
\text { against } C \text {. perfringens }\end{array}$ & [56] \\
\hline & $\begin{array}{l}\text { C. ramosum, C. asparagiforme, C. indolis, C. } \\
\text { hathewayi, C. bolteae, Clostridiales 1_7_47FAA, } 2 \times \\
\text { Clostridium species, C. scindens, Clostridiaceae } \\
\text { JC13, } 3 \times \text { Lachnospiraceae species, B. producta, E. } \\
\text { fissicatena, Ruminococcus sp. ID8, A. colihominis }\end{array}$ & $\begin{array}{l}\text { Impact of microbiota on chronic } \\
\text { intestinal inflammation }\end{array}$ & [57] \\
\hline
\end{tabular}


Table 2. Cont.

\begin{tabular}{|c|c|c|c|}
\hline Syncom & Composition & Application/Research Question & Ref. \\
\hline & \multirow{2}{*}{$\begin{array}{l}\text { B. caccae, B. ovatus, B. theta }{ }^{1} \text {, B. uniformis, B. } \\
\text { vulgatus, B. cellulosilyticus WH2, C. scindens, C. } \\
\text { spiroforme, C. aerofaciens, D. longicatena, E. rectale, } \\
\text { F. prausnitzii, P. distasonis, R. obeum, R. torques }\end{array}$} & Microbe-diet interaction & [43] \\
\hline & & Microbe-microbe interactions & [44] \\
\hline & $-E$. rectale, $-F$. prausnitzii, $-R$. torques & Microbe-diet interaction & [58] \\
\hline & $\begin{array}{l}\text { B. caccae, B. ovatus, B. theta }{ }^{1} \text {,E. rectale, C. } \\
\text { aerofaciens, C. symbiosum, E. coli, M. formatexigens }\end{array}$ & \multirow{2}{*}{$\begin{array}{l}\text { Microbe-diet interaction and impact on } \\
\text { metabolism }\end{array}$} & [59] \\
\hline & $+D$. piger,+ E. rectale,$+B$. hydrogenotrophica & & [60] \\
\hline B4PC2 & $\begin{array}{l}\text { B. uniformis, B. vulgatus, B. producta, } \\
\text { P. distasonis, C. hylemonae, C. hiranonis }\end{array}$ & $\begin{array}{l}\text { Host-microbe metabolic cross-talk and } \\
\text { bile acid metabolism }\end{array}$ & {$[61,62]$} \\
\hline
\end{tabular}

${ }^{1}$ Abbreviations: B. theta-B. thetaiotaomicron.

When selecting synthetic consortia to conduct studies, it is important to consider not only whether to use human-derived or host-specific community but also which life stage is addressed in this study. The majority of available minimal microbial consortia recapitulate the microbial composition or microbial signatures found in the adult fecal microbiome. However, the microbial composition of the gut microbiota differs greatly between different age stages due to alimentary and environmental factors [63-65]. Therefore, it is important to assemble age-specific consortia as well as to distinguish between the infant, adult, and elderly microbiome. A few years ago, Luk et al. generated a simplified model community of the human infant gut microbiota comprised by four Bifidobacterium species with high abundance in healthy infants but low abundance in adults [55]. This infant-specific syncom includes Bifidobacterium longum subsp. infantis S12, Bifidobacterium breve S50 (Variant a), Bifidobacterium bifidum $\mathrm{Ti}$, and Bifidobacterium dentium B757. Using this syncom, the authors investigated the effects of infant-type Bifidobacteria on brain function including recognition memory, as early-life gut colonization was shown to be involved in the development of the central nervous system via the microbiota-gut-brain axis [66]. The study results demonstrated that neonatal colonization with the human infant microbiota containing Bifidobacteria exerted similar beneficial neuromodulatory effects in gnotobiotic mice as colonization with complex microbiota. Moreover, Bifidobacteria particularly improved recognition memory [55]. These findings of bacteria-derived beneficial effects on the brain may contribute to the development of novel microbiota-based therapeutic interventions for human neurodevelopmental disorders.

Altogether, synthetic microbiomes represent modular systems that allow various combinations of intestinal isolates based on their function to mimic physiological conditions of interest.

\section{Utilizing Syncoms to Model Gut Disease Phenotypes}

Apart from the synthetic communities mimicking indigenous gut microbiota, diseasespecific consortia have been assembled for application in germ-free animals to identify and define the causal role of bacteria in the pathogenesis of human disorders. In the next paragraphs, we give an overview of existing human- and rodent-derived syncoms utilized in mechanistic studies to untangle disease-associated host-microbe interactions (Tables 1 and 2). Moreover, here, we only focus on the development of enteropathies categorized in infectious, inflammatory, and metabolic diseases as well as colorectal cancer.

\subsection{Infectious Diseases}

The intestinal microbiota prevents the overgrowth of potentially pathogenic microorganisms and thus protects intestinal tissues from microbial invasion $[67,68]$. However, diverse environmental conditions, such as antibiotic application or contaminated food, 
can damage the stability and functionality of the intestinal barrier. The resulting enteric impairment can lead to the typical symptoms of infectious colitis such as nausea, vomiting, and diarrhea. Even though infection rates in the Western world have reduced dramatically over the past century due to advances in hygiene, antibiotics, and vaccination, infectious diseases of the gut induced by bacteria, viruses, or even parasites are still among the most frequent causes of medical treatment worldwide [69]. A typical secondary manifestation after antibiotic treatment is, e.g., the overgrowth of Clostridioides difficile (former Clostridium difficile) in the intestine, which can lead to infectious colitis due to the impaired intestinal defenses [70,71]. Although $\mathrm{OMM}^{12}$ shows typical characteristics of the normal complex microbiome by providing colonization resistance against some enteric pathogens such as Salmonella enterica serovar Typhimurium, it does not exhibit resistance to C. difficile infection (CDI) [36]. Metabolic analyses of $\mathrm{OMM}^{12}$ members confirmed the deficiency for the $7 \alpha$-dehydroxylation, bacterial transformation producing secondary bile acids, deoxycholic and lithocholic acid [36]. These microbial metabolites are associated with protection against pathogen colonization such as C. difficile [72]. Modulation of $\mathrm{OMM}^{12}$ with the $7 \alpha$-dehydroxylating commensal Clostridium scindens strain ATCC35704 resulted in physiological bile acid composition in the large intestine and protected against CDI. Interestingly, secondary bile acids are absent in mice monocolonized with $C$. scindens, indicating that this Clostridium species requires the presence of other intestinal microbes for certain metabolic processes [73]. As C. scindens can only metabolize unconjugated bile acids, the deconjugation of bile acids was carried out by the $\mathrm{OMM}^{12}$ community, which in turn resulted in transient protection against CDI [36]. This study describes how already established syncoms can be modified to generate communities specifically tailored for the study demand. Furthermore, metabolic cross-talk between commensals and the host can be explored in more detail in models associated with syncoms. Crost et al. investigated defense mechanisms of the intestinal microbiota against pathogenic Clostridium species. In this study, the authors established a syncom containing bacteria that are involved in the colonization resistance against the opportunistic pathogen Clostridium perfringens, which causes foodborne disease in humans, to identify metabolites mediating this protective effect [56]. This simplified syncom included four cultivable bacteria Ruminococcus gnavus E1, Bacteroides thetaiotaomicron LEMF4, Clostridium hathewayi LEMC7, and Clostridium orbiscindens LEMH9, and it was able to stably colonize the digestive tract of rodents. To identify metabolites mediating colonization resistance, different combinations of these bacteria were challenged with C. perfringens in vivo. A diffusible trypsin-dependent bactericidal substance produced by the R. gnavus E1 strain was identified as a key metabolite for C. perfringens elimination. However, this protective effect mediated by R. gnavus E1 was dependent on the presence or absence of other bacteria in the consortium [56]. Another mechanism of protection from infectious enteric diseases is to strengthen the host's intestinal defense. The Microbial Ecosystem Therapeutic (MET-1) consortium was developed by isolating 33 bacteria from healthy human stool. This consortium was initially used to cure patients with recurrent CDI. Martz et al. hypothesized that MET-1 might also protect against other systemic infectious agents, such as S. enterica serovar Typhimurium. In this study, the authors found that MET-1 does not inhibit the growth of S. enterica serovar Typhimurium in the intestine. However, the application of MET-1 strengthened the host intestinal barrier function by increasing tight junction gene expression, attenuating the infiltration of immune cells in the intestinal mucosa, and reducing the local expression level of pro-inflammatory cytokines. As a result, the intestine was protected from severe tissue damage, and systemic spread of the bacteria was prevented [54]. Thus, MET-1 syncom could be used as novel strategy of microbiota-based therapy to protect against the severe disease outcome after S. enterica serovar Typhimurium infection. In one other study using gnotobiotic mice associated with the OMM ${ }^{12}$ consortium, bacterium $M$. schaedleri was found to protect a genetically predisposed host against Salmonella-induced colitis. The protective effect mediated by M. schaedleri involved the inhibition of Salmonella virulence factor expression and competition for anaerobic respiration substrates in the gut [38]. However, certain bacterial 
composition of intestinal microbiota may not always exert a beneficial effect on the host but may also be associated with the development of enteric disorders or their exacerbation. By using a well-defined gnotobiotic mouse model colonized with SHUMIx, Ganesh et al. investigated whether an additional enteric commensal $A$. muciniphila influences the inflammation induced by $S$. enterica serovar Typhimurium $[40,51]$. A. muciniphila belongs to the Verrucomicrobia phylum and has mucolytic property through the enzymatic degradation of mucin [74]. Thus, it is hypothesized that A. municiphila can play a role in the development of intestinal inflammation. Indeed, the co-colonization of $A$. muciniphila in $S$. enterica serovar Typhimurium-infected SIHUMIx mice caused exacerbated colon histopathology and increased levels of pro-inflammatory cytokines. Additionally, vast alterations of the SIHUMIx bacterial composition were caused by the intestinal presence of $A$. muciniphila and S. enterica serovar Typhimurium. In the presence of $A$. muciniphila, S. enterica serovar Typhimurium was able to suppress the dominating bacterial taxa Bacteroides thetaiotaomicron [51]. Due to excessive mucin degradation by $A$. municiphila, luminal antigens can gain access to the intestinal mucosa and stimulate the host immune system and the production of antimicrobial peptides that can in turn cause changes in the microbiota composition. On the other hand, due to mucus layer degradation by A. muciniphila, S. enterica serovar Typhimurium can more easily reach the underlying tissue and induce inflammatory lesions. However, the microbial capacity to exacerbate acute intestinal inflammation is not only a species-specific feature but is also influenced by the bacterial strain. The symbiont Escherichia coli is commonly found in the digestive tract of mammals worldwide. Although this bacterium is an obligate component of healthy human microbiota, it can also cause enteric and extraintestinal disease, depending on the strain of E. coli. Thus, Kittana et al. analyzed the effects of different $E$. coli strains isolated from healthy conventional mice in a chemically triggered gnotobiotic mouse model of inflammatory bowel disease (IBD). While some E. coli strains (isolates ST150 and ST468) exerted a neutral effect on induced inflammation in ASF colonized mice, other strains (isolates ST129 and ST375) exacerbated inflammatory lesions in the gut [33]. This observation indicated that not only the species but also the strain should be considered in host-microbiota studies, since different strains can interact differently with the host resulting in neutral, beneficial, or detrimental effect.

\subsection{Inflammatory Diseases}

In many experimental models of intestinal inflammation, animals are free of diseasespecific signs under germ-free conditions indicating that the gut microbiota is crucial for disease pathogenesis [75-78]. To determine whether single or even groups of microbes affect the onset and severity of the disease, functional studies using defined intestinal consortia are required. Using the SIHUMIx community, Ring et al. investigated whether A. muciniphila strain ATCC BAA-835 promotes the development of intestinal inflammation [50]. There are contradictory studies reporting both beneficial and detrimental effects of this bacterium in the context of intestinal inflammation $[51,79,80]$. Furthermore, the intestinal abundance of $A$. muciniphila is mainly associated with beneficial effects in terms of metabolic disease outcome [81-83]. The colonization of germ-free interleukin 10 (IL10)deficient mice, a model for experimental IBD, with SIHUMIx syncom caused histopathological changes in the intestine. Amendment of the SIHUMIx consortium with A. muciniphila did not exacerbate colitis nor influence the abundance of SIHUMIx members [50]. This study confirmed that the $A$. muciniphila ATCC BAA-835 strain does not promote chronic intestinal inflammation in gnotobiotic mice genetically predisposed to colitis. Eun et al. developed another SIHUMI microbiota to study IBD-related microbiota-host interactions. The bacteria were selected based on their altered abundance in patients with IBD and healthy individuals, ability to affect experimental colitis, human origin, and ability to stably colonize rodents [52]. The community is composed of seven bacterial taxa including Enterococcus faecalis OG1RF, Ruminococcus gnavus ATCC 29149, Faecalibacterium prausnitzii A2-165, Lactobacillus plantarum WCFS1, Bacteroides vulgatus ATCC 8482, Escherichia coli LF82, and Bifidobacterium longum subsp. longum ATCC 15707. When this consortium was introduced 
into germ-free experimental models of IBD, it promoted colitis development [52]. The colitogenic contribution of E. faecalis within the SIHUMI consortium was characterized by comparing SIHUMI-associated mice lacking this bacterium with animals carrying the complete syncom [53]. Surprisingly, the deletion of E. faecalis resulted in more severe colitis characterized by increased histopathological tissue lesions and higher expression levels of pro-inflammatory cytokines, suggesting that this opportunistic pathogen provides a beneficial effect within this IBD-related consortium. Moreover, this observation demonstrated that interactions with co-colonizing bacteria may reprogram the pro-inflammatory activity of E. faecalis [53]. Viral infections such as norovirus infection were also associated with exacerbated colitis symptoms in experimental models of colitis as well as IBD patients [34,84-86]. However, studies using gnotobiotic models or depleted microbiota demonstrated that the colitogenic stimulus of norovirus depends on the presence of enteric microbiota $[34,84]$. Norovirus infection exacerbated intestinal inflammation in both ASF syncom and complex microbiota colonized IL10-deficient mice. In contrast, germ-free IL10-deficient mice did not develop colitis after norovirus infection [34]. A subsequent study investigated the contribution of bacterial composition to viral-triggered intestinal inflammation by comparing two different syncoms, ASF and $\mathrm{OMM}^{12}$ [23]. In this study, norovirus infection exacerbated colitis only in IL10-deficient mice carrying ASF but not those colonized with $\mathrm{OMM}^{12}$. Additionally, the modulation of these syncoms with immunomodulatory segmented filamentous bacteria (SFB) abolished intestinal inflammation in mice associated with ASF despite norovirus infection. The SFB-mediated protective effect was associated with enhanced intestinal barrier defenses [23]. Altogether, this showed that the composition of intestinal microbiota determines the outcome of disease.

In terms of host-mediated factors, the impaired intestinal epithelial barrier function in IBD patients allows the entry of luminal bacteria into the gut tissue, inducing an inflammatory immune response $[87,88]$. To address the mechanisms causing chronic colon inflammation in response to epithelial barrier defects, Eftychi et al. used gnotobiotic mice with intestinal epithelial cell-specific deficiency of nuclear factor- $\mathrm{kB}$ essential modulator (NEMO). Colitis development in this model is microbiota-driven. In this study, the nonpathogenic commensal syncom ASF alone was sufficient to trigger chronic inflammation by promoting the release of pro-inflammatory cytokines IL-12, IL-23, and IFN- $\gamma$. In the early stages of the disease, colitis was driven by IL-12, whereas the inflammation in later stages was driven by IL-23. These results suggest that similar mechanisms might contribute to IBD pathogenesis, especially in patients with impaired intestinal barrier [32]. Due to its crucial role in the development of inflammation, modulation of the gut microbiota holds great promise for the treatment of patients with chronic inflammatory disorders. As an example of a therapeutic syncom, Atarashi et al. assembled a defined, complex bacterial mixture of Clostridium strains, particularly clusters IV and XIVa isolated from human stool [57]. These bacteria were selected based on their high potency in enhancing regulatory $\mathrm{T}$ cell immune response, driving the resistance to IBD and allergies. The underlying molecular mechanism was attributed to the production of bacterial metabolites such as SCFA, which induce regulatory $\mathrm{T}$ cells in the colonic mucosa [89]. The characterization of these metabolites, including their mechanistic interaction with the host, may allow targeted therapeutic manipulation of intestinal dysbiosis.

\subsection{Metabolic Disorders}

The gastrointestinal tract of healthy individuals serves as a biotope and nutritional source for varieties of microbial species. In this symbiotic relationship, the host benefits from hundreds of bacterial genes not present in the human genome that enable the extraction of essential nutrients from food that would otherwise not be used by the body [1]. The bacterial production of metabolites such as beneficial SCFA (butyrate, acetate, and propionate) is a main source of energy for the host colonocytes, but these are also required for the maintenance of the intestinal and immune homeostasis [90]. As microbial-derived metabolites have an immense modulating impact on intestinal physiology and host metabolism, 
dysbiosis-associated changes in microbiota composition can lead to the development of metabolic diseases [5]. In this context, the composition of the human microbiome is shaped by environmental factors such as antibiotic treatments, stress, and unhealthy diet, which can cause dysbiosis, leading to a breakdown of intestinal homeostasis [91-94]. Thus, due to increasing incidence of metabolic diseases such as type 2 diabetes and obesity, research efforts focus on deciphering the influence of diet in shaping the microbiome. Each bacterium has its metabolic profile and, depending on the availability of macromolecules derived from diet, the composition and diversity of the microbiota change [95-97]. However, so far, only an association between the prevalence of certain diseases and specific eating habits has been established. For example, a Western diet (obesity-associated diet) rich in carbohydrates and fats causes an adaptive shift in the abundance of bacterial communities by favoring those having increased capacity to harvest energy from the diet [98]. Thus, the characterization and modulation of microbial metabolic activity could help to create novel therapies for treating metabolic diseases. Hence, the use of gnotobiotic animal models in combination with defined nutritional formulas is essential to explore diet-derived changes of the microbiota and their influence on the energy balance. This approach allows hypothesis-driven, simplified, and controlled studies under highly standardized microbial conditions. The SIHUMIx consortium represents a valuable and frequently used gnotobiotic model to explore metabolic dysfunction, particularly with regard to obesity [40]. Using this syncom, it was demonstrated that the SIHUMIx member C. ramosum promotes high-fat diet-induced obesity [48]. The underlying mechanism of the bacteria-related obesogenic potential was attributed to the upregulation of glucose and fat transporters in the small intestine, resulting in increased diet digestibility and body fat deposition. Furthermore, Woting et al. also investigated whether B. longum within the SIHUMIx consortium was able to mediate the diet-induced improvement of obesity symptoms. Previous studies reported that the oligofructose ameliorates obesity by promoting the growth of intestinal Bifidobacteria $[99,100]$. Woting et al. showed that the oligofructose supplementation reduced obesity by decreasing body fat accumulation and improving glucose tolerance, but this beneficial effect was independent of the presence of B. longum [101]. Using the same community, Weitkunat et al. investigated the effects of dietary fibers on lipid metabolism [49]. An excess production of SCFA derived from the microbial fermentation of indigestible fibers was reported to promote obesity [102,103]. Thus, gnotobiotic mice associated with SIHUMIx were fed a high-fat diet supplemented with either fermentable (inulin) or nonfermentable (cellulose) fibers [49]. As inulin serves as a substrate for enteric bacteria, feeding the inulin-supplemented diet affected the intestinal SIHUMIx consortium. All SIHUMIx members except E. coli and L. plantarum increased in numbers, leading to increased SCFA production with a reduced cecal acetate/propionate ratio compared to cellulose-fed mice. Interestingly, additional energy extraction from the inulin diet did not increase fat deposition and body weight but led to an increased bacterial proliferation. Furthermore, inulin feeding positively influenced lipid metabolism by decreasing the hepatic expression of genes involved in lipogenesis and fatty acid elongation/desaturation, changing plasma and liver phospholipid composition, and increasing omega-3:omega-6 fatty acid ratio. Altogether, these data suggest beneficial effects of inulin on preventing obesity [49]. Although dietary cellulose had no effect on the outcome of obesity, another study demonstrated its impact on components of the intestinal immune system resulting in the inhibition of colitis induction [37]. By feeding conventional mice fiber-free diets, the intestinal abundance of Alistipes genus was strongly reduced. To investigate the causal relationship of this bacterium to cellulose-mediated protection, Oligo-MM ${ }^{12}$ syncom was refined by adding Alistipes finegoldii, which is a bacterium that can metabolize cellulose into glucose. In this system, dietary cellulose modified the gene expression of the intestinal epithelium in favor of anti-inflammatory immunity, ensuring intestinal homeostasis. Thus, the co-colonization of Oligo-MM $\mathrm{MM}^{12}$ syncom with $A$. finegoldii decreased the sensitivity to chemically induced colitis development. Analyses of colonic tissue revealed minimized inflammatory lesions that were the result of the strengthened intestinal barrier function through the increased 
expression of regulatory cytokines and epithelium-enhancing proteins [37]. Altogether, this study supports the reported health-promoting effects of dietary cellulose by providing causal mechanisms in a gnotobiotic animal model. McNulty et al. analyzed the impact of dietary supplements in terms of commercially available probiotics on the indigenous gut microbiome [43]. For this purpose, a synthetic minimal microbiome containing 15 sequenced gut symbionts belonging to three principal bacterial phyla of human microbiota (six Bacteroides species, two Clostridium species, Collinsella aerofaciens, Dorea longicatena, Eubacterium rectale, Faecalibacterium prausnitzii, Parabacteroides distasonis, and two Ruminococcus species) was assembled. Microbial species were selected based on their representative abundance in the human gut and their functional similarity to microbial features observed in the healthy adult fecal microbiome. Gnotobiotic mice associated with the 15-member syncom were treated with probiotic fermented milk product (FMP) containing Bifidobacterium animalis subsp. lactis, two strains of Lactobacillus delbrueckii subsp. bulgaricus, Lactococcus lactis subsp. cremoris, and Streptococcus thermophilus. Metatranscriptomic and metabolic analyses were performed to characterize the impact of the probiotic consortium on the established model microbiome. Members of FMP successfully colonized the murine intestine, causing only minor shifts in the indigenous community. Furthermore, the introduced FMP bacteria enriched the model syncom by providing microbial enzymes involved in diverse metabolic processes such as the fermentation of specific carbohydrates. These experiments showed that synthetic microbiomes can be used as a translational pipeline for characterizing the effects of FMPs on the human microbiome [43]. In a further study by the same research group, the model human consortium comprising now twelve sequenced gut bacterial species was used to analyze the effect of diet on endogenous microbiota. Gnotobiotic mice colonized with artificial human-derived community were fed by oscillating diets of contrasting composition (low-fat/high-plant polysaccharide and high-fat/high-sugar diet) that induced rapid, reproducible, and reversible changes in the microbial community structure [58]. Thus, this bacterial consortium can also serve as a model human gut community providing similar metabolic functions to describe the interactions of indigenous intestinal microbes with environmental factors such as diet. Depending on the research hypothesis and investigated dietary formula, the model human consortium was accordingly modified in its microbial composition to dissect the metabolic niche and contribution of each community member to the host metabolism [59,60]. Narushima et al. designed a six-member syncom, B4PC2, by combining human fecal isolates capable of metabolizing bile acids (Bacteroides uniformis, Bacteroides vulgatus, Clostridium hylemonae TN-271, Clostridium hiranonis TO-931, Parabacteroides distasonis, and Blautia producta). Experiments employing this human-derived syncom demonstrated that human gut microbes can metabolize conjugated primary bile acids into secondary bile acids in vivo [61]. By revisiting this model using omic technologies, the transcriptional profiles of each bacterium within this consortium were defined, revealing the expression of bacterial genes involved in bile acid metabolism [62]. Bile acids not only affect the structure and function of the gut microbial community but also play an important role in host health and disease such as gallstone disease, IBD, and CDI $[93,104-106]$. As the ingested food/diet affect the gut microbiota and the host bile acid signature, it is important to decipher interactions between diet and intestinal microbiota to create new dietary guidelines for individuals of various life stages and health status.

\subsection{Colorectal Cancer}

Several studies using humanized cancer-related animal models after fecal microbiota transfer showed that tumor incidence is strongly associated with the bacterial composition of the human inoculum and independent of the donor health status [107]. These findings indicated that the initial community structure of the gut microbiome of the recipient mice might trigger colorectal cancer. The complex fecal microbiota transfer in germ-free mice is still predominantly used as a model to assess microbiota contribution to the development of colorectal cancer [108-112]. However, to determine the specific contribution of individual bacteria to colorectal cancer development, it is important to create cancer-related syncoms 
providing controlled and standardized research conditions. In this line, Donohoe et al. used a gnotobiotic mouse model associated with four commensal members of the ASF consortium, which were fed with a high-fiber diet to demonstrate that fibers do have a potent tumor-suppressive effect [35]. By amending the four-ASF syncom with the butyrateproducing bacterium, Butyrivibrio fibrisolvens, the gnotobiotic mice developed fewer and less-advanced colonic tumors. However, fibers suppressed colorectal cancer development in a microbiota- and butyrate-dependent manner [35]. Even though the number of studies using syncoms in the current colorectal microbiome research is still sparse, this model has a great potential to determine the ability of particular microbiota members to modulate colorectal cancer development.

\section{Differences between Human-Derived and Model-Specific Communities}

In the above sections, the use of different syncoms and their modulations in the microbiome research was described. However, the described syncoms not only differ in their bacterial composition and function but also in the origin of the selected bacteria. Thus, in this section, the advantages and limitations of human-derived or model-specific communities will be addressed.

The use of human-derived bacterial consortia in gnotobiotic animal models allows performing standardized experiments that cannot be performed in humans. Currently, the predominantly used gnotobiotic animal models are gnotobiotic mice (Figure 2). In this context, gnotobiotic models are highly controlled in regard to their microbial environment and diet as well as genetically standardized by using inbred strains. Additionally, numerous genetically modified mouse strains are available, which allow mechanistic studies of particular molecules and pathways. Despite some limitations, the application of gnotobiotic mouse models colonized with human-derived microbes contributes to the deciphering of the functional role of human microbiota. Although the gut microbiota between humans and laboratory mice is qualitatively similar, there are large quantitative differences [113]. Studies showed that the relative proportion between Firmicutes and Bacteriodetes (F/B ratio) has an impact on human health status, as shifts in this ratio were associated with the development of different disorders, such as obesity (increased F/B ratio) and IBD (decreased F/B ratio) [114,115]. However, the physiological F/B ratio differs between humans and mice. Phylum-level analyses demonstrated a higher F/B ratio in humans than in mice that potentially could interfere with the interpretation of microbial shifts in humanized mice [116]. Furthermore, some microbes are host-specific and cannot colonize other species $[113,117,118]$. These inter-species variations also influence the microbial metabolism, resulting in dissimilar bacteria-derived metabolite composition [119-121]. Thus, the loss of these host-specific microbial products in humanized mice may affect the host physiology [120]. An important issue to mention here is also the complex host-specific cross-talk between individuals and their microbiota, which influences the development and maturation of the intestinal immunology and physiology $[122,123]$. Hereby, the enteric colonization shapes the mucosal immune system, which in turn forms the intestinal microbiota $[89,124]$. Thus, the colonization of non-human hosts with human-derived taxa could lead to an atypical maturation of the host immune system [117]. Additionally, the loss of certain bacterial species or shifts in the microbial abundance was observed when the bacterial consortium was transferred into a host with which it has not co-evolved [125]. However, this host-derived effect was not very pronounced in human-microbiota-associated mice $[39,117,125]$. One way to circumvent these differences is to assess the functionality of the gut microbiome in a host-specific manner. The prerequisite for this approach is the availability of model-specific collections of microbial isolates. To this end, the mouse $(\mathrm{miBC})$ and pig (piBAC) intestinal bacterial collections were recently created $[14,16]$. These public repositories include all cultivable bacterial strains from the mouse and pig intestine that are publicly available with the aim of supporting colonization experiments by providing a collection of well-described commensal strains. Moreover, the engraftment of human-specific microbes is improved in species that share more similarities with humans 
such as gnotobiotic rats or pigs [126]. In this line, a study by Wos-Oxley et al. showed that the colonization efficiency of human taxa is higher in gntotobiotic rats than in gnotobiotic mice [118]. Currently, the use of other gnotobiotic species in microbiome research is still limited, which is mainly due to the high maintenance costs, lower reproduction rate, as well as restricted availability of knockout models and reagents such as antibodies. How ever, their relevance will increase in the future, especially the use of gnotobiotic pigs as a clinically relevant model.

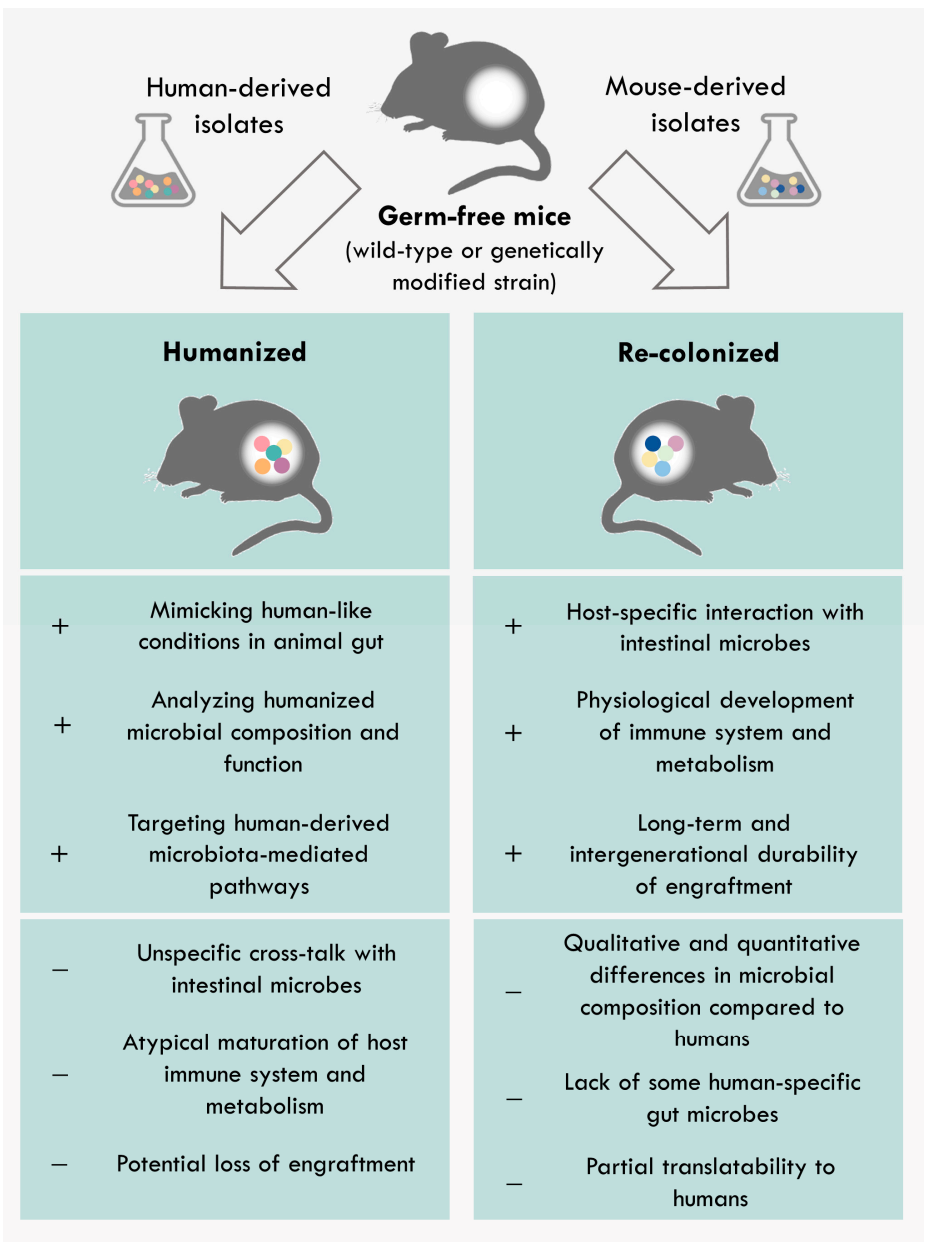

Figure 2. Advantages/limitations of gnotobiotic animals colonized with human-derived or modelderived communities. Predominantly used gnotobiotic animal models are gnotobiotic mice. Gnotobiotic mice are highly controlled in regard to their microbial environment, genetics, and diet. Germ-free mice can be associated with human-derived or mouse-derived communities to perform mechanistic studies to decipher microbial role in the host physiology or pathology under highly standardized conditions.

\section{Conclusions and Future Prospective}

The generation of minimal microbiomes and their application in gnotobiotic models allows mechanistic investigations of host-microbe interactions under controlled conditions. However, the development of novel synthetic minimal communities, as well as the refinement of already existing ones to the latest scientific findings, is essential to untangle the underlying mechanisms of host-microbiota interactions and their role in host health and disease. Syncoms represent a valuable compromise between the non-translatability of colonization with single microbial species and the huge complexity of conventional unknown microbiota. The aim of minimal microbiomes utilization is to reduce this complexity to a manageable level, allowing addressing well-defined functional questions and demonstrat- 
ing the causality of microbiota-associated phenotypes. Thus, the field is streaming to design representative minimal microbiomes that can recapitulate functions of the complex microbiomes. Studies have shown that the intestinal microbiota harbors important keystone taxa, which have a pivotal role in the ecosystem dynamics by dominating inter-microbial interaction networks. In this context, these certain keystone species influence community composition, functionality, and stability, as their absence can lead to intestinal imbalances [127]. In the case of disease-associated syncoms, the microbial community should also best reflect the phenotype, including clinical signs, tissue-specific pathology, and similarities in pathogenesis. Compared to complex fecal microbiota transfer using stool samples with unknown microbiota composition, the application of syncoms is controllable, standardized, and reproducible because of the defined microbial composition based on specific bacterial features, not only the donor's phenotype. Additionally, the pure bacterial mixture is more stable than the fecal inoculum for the colonization of germ-free animals $[30,128]$. However, by simplifying intestinal microbial communities, the risk of not recapitulating microbiota signatures and phenotypes increases. To prevent the loss of microbiota-mediated phenotypes, it is essential to design more complex syncoms. In this context, the prerequisite for refining synthetic microbiota is the isolation and characterization of still uncultured microbial species, not only bacteria, but also viruses, fungi, phages, and archaea that are part of the indigenous complex microbiota. Despite the high inter-individual variability, up to $65 \%$ of molecular species detected by the sequencing of mouse and human complex gut communities have representative strains in culture. However, numerous taxa representing a source of novel functions are still undiscovered $[129,130]$. Furthermore, the augmentation of syncoms with non-bacterial species that affect host metabolism, immune response, and physiological processes will improve the functional recapitulation of complex microbial communities. Thus, it is essential to further support initiatives aiming to establish or maintain already existing collections and databases of human and model-specific microbial isolates [14-16,131,132]. The availability of well-described intestinal microbial isolates will contribute to the creation of robust experimental models in which generated hypotheses can be tested by systemic manipulations of specific variables. Hence, the combination of gnotobiotic and multi-omic approaches-particularly, transcriptomics, metabolomics, and proteomics-will provide improved insight into the cause-effect relationship between the microbes and the host that is a prerequisite to efficiently translate microbiome research into clinical application. Comprehensive understanding of host-microbe and microbemicrobe interactions is fundamental for the development of novel therapeutics, which will enable a non-invasive targeted modulation of the intestinal microbiota. Future medication could consist of e.g., microbial metabolites or derivatives that effectively abolish intestinal imbalance while reducing the systemic side effects compared to antibiotics.

Author Contributions: Conceptualization, M.B. and S.B.; Writing-original draft preparation, S.B. and M.B.; Writing—review and editing, M.B. and S.B.; Visualization, M.B. and S.B.; Funding acquisition, M.B. and A.B. All authors have read and agreed to the published version of the manuscript.

Funding: This research was supported by the Joint Action "European Joint Programming Initiative "A Healthy Diet for a Healthy Life" (JPI HDHL)" and the respective national/regional funding organization: Federal Ministry of Education and Research (BMBF, FKZ 01EA1906F) and the German Research Foundation (DFG) - project number 395357507-“SFB 1371”.

Conflicts of Interest: The authors declare no conflict of interest.

\section{References}

1. Qin, J.; Li, R.; Raes, J.; Arumugam, M.; Burgdorf, K.S.; Manichanh, C.; Nielsen, T.; Pons, N.; Levenez, F.; Yamada, T.; et al. A human gut microbial gene catalogue established by metagenomic sequencing. Nature 2010, 464, 59-65. [CrossRef] [PubMed]

2. Frank, D.N.; St Amand, A.L.; Feldman, R.A.; Boedeker, E.C.; Harpaz, N.; Pace, N.R. Molecular-phylogenetic characterization of microbial community imbalances in human inflammatory bowel diseases. Proc. Natl. Acad. Sci. USA 2007, 104, 13780-13785. [CrossRef] [PubMed]

3. Wu, H.J.; Ivanov, I.I.; Darce, J.; Hattori, K.; Shima, T.; Umesaki, Y.; Littman, D.R.; Benoist, C.; Mathis, D. Gut-residing segmented filamentous bacteria drive autoimmune arthritis via T helper 17 cells. Immunity 2010, 32, 815-827. [CrossRef] 
4. Wen, L.; Ley, R.E.; Volchkov, P.Y.; Stranges, P.B.; Avanesyan, L.; Stonebraker, A.C.; Hu, C.; Wong, F.S.; Szot, G.L.; Bluestone, J.A.; et al. Innate immunity and intestinal microbiota in the development of Type 1 diabetes. Nature 2008, 455, 1109-1113. [CrossRef]

5. Ussar, S.; Griffin, N.W.; Bezy, O.; Fujisaka, S.; Vienberg, S.; Softic, S.; Deng, L.; Bry, L.; Gordon, J.I.; Kahn, C.R. Interactions between Gut Microbiota, Host Genetics and Diet Modulate the Predisposition to Obesity and Metabolic Syndrome. Cell Metab. 2015, 22, 516-530. [CrossRef]

6. Lee, Y.K.; Menezes, J.S.; Umesaki, Y.; Mazmanian, S.K. Proinflammatory T-cell responses to gut microbiota promote experimental autoimmune encephalomyelitis. Proc. Natl. Acad. Sci. USA 2011, 108 (Suppl. 1), 4615-4622. [CrossRef]

7. Liang, Q.; Chiu, J.; Chen, Y.; Huang, Y.; Higashimori, A.; Fang, J.; Brim, H.; Ashktorab, H.; Ng, S.C.; Ng, S.S.M.; et al. Fecal Bacteria Act as Novel Biomarkers for Noninvasive Diagnosis of Colorectal Cancer. Clin. Cancer Res. 2017, 23, 2061-2070. [CrossRef]

8. Surana, N.K.; Kasper, D.L. Moving beyond microbiome-wide associations to causal microbe identification. Nature 2017, 552, 244-247. [CrossRef]

9. Gilbert, J.A.; Quinn, R.A.; Debelius, J.; Xu, Z.Z.; Morton, J.; Garg, N.; Jansson, J.K.; Dorrestein, P.C.; Knight, R. Microbiome-wide association studies link dynamic microbial consortia to disease. Nature 2016, 535, 94-103. [CrossRef]

10. Basic, M.; Bleich, A. Gnotobiotics: Past, present and future. Lab. Anim. 2019, 53, 232-243. [CrossRef] [PubMed]

11. Tlaskalova-Hogenova, H.; Stepankova, R.; Kozakova, H.; Hudcovic, T.; Vannucci, L.; Tuckova, L.; Rossmann, P.; Hrncir, T.; Kverka, M.; Zakostelska, Z.; et al. The role of gut microbiota (commensal bacteria) and the mucosal barrier in the pathogenesis of inflammatory and autoimmune diseases and cancer: Contribution of germ-free and gnotobiotic animal models of human diseases. Cell Mol. Immunol. 2011, 8, 110-120. [CrossRef] [PubMed]

12. Stecher, B.; Berry, D.; Loy, A. Colonization resistance and microbial ecophysiology: Using gnotobiotic mouse models and single-cell technology to explore the intestinal jungle. FEMS Microbiol. Rev. 2013, 37, 793-829. [CrossRef] [PubMed]

13. Clavel, T.; Gomes-Neto, J.C.; Lagkouvardos, I.; Ramer-Tait, A.E. Deciphering interactions between the gut microbiota and the immune system via microbial cultivation and minimal microbiomes. Immunol. Rev. 2017, 279, 8-22. [CrossRef]

14. Lagkouvardos, I.; Pukall, R.; Abt, B.; Foesel, B.U.; Meier-Kolthoff, J.P.; Kumar, N.; Bresciani, A.; Martinez, I.; Just, S.; Ziegler, C.; et al. The Mouse Intestinal Bacterial Collection (miBC) provides host-specific insight into cultured diversity and functional potential of the gut microbiota. Nat. Microbiol. 2016, 1, 16131. [CrossRef] [PubMed]

15. Poyet, M.; Groussin, M.; Gibbons, S.M.; Avila-Pacheco, J.; Jiang, X.; Kearney, S.M.; Perrotta, A.R.; Berdy, B.; Zhao, S.; Lieberman, T.D.; et al. A library of human gut bacterial isolates paired with longitudinal multiomics data enables mechanistic microbiome research. Nat. Med. 2019, 25, 1442-1452. [CrossRef] [PubMed]

16. Wylensek, D.; Hitch, T.C.A.; Riedel, T.; Afrizal, A.; Kumar, N.; Wortmann, E.; Liu, T.; Devendran, S.; Lesker, T.R.; Hernandez, S.B.; et al. A collection of bacterial isolates from the pig intestine reveals functional and taxonomic diversity. Nat. Commun. 2020, 11, 6389. [CrossRef] [PubMed]

17. Mabwi, H.A.; Kim, E.; Song, D.G.; Yoon, H.S.; Pan, C.H.; Komba, E.V.G.; Ko, G.; Cha, K.H. Synthetic gut microbiome: Advances and challenges. Comput. Struct. Biotechnol. J. 2021, 19, 363-371. [CrossRef]

18. Schaedler, R.W.; Dubs, R.; Costello, R. Association of Germfree Mice with Bacteria Isolated from Normal Mice. J. Exp. Med. 1965, 122, 77-82. [CrossRef] [PubMed]

19. Schaedler, R.W.; Dubos, R.; Costello, R. The Development of the Bacterial Flora in the Gastrointestinal Tract of Mice. J. Exp. Med. 1965, 122, 59-66. [CrossRef] [PubMed]

20. Wymore Brand, M.; Wannemuehler, M.J.; Phillips, G.J.; Proctor, A.; Overstreet, A.M.; Jergens, A.E.; Orcutt, R.P.; Fox, J.G. The Altered Schaedler Flora: Continued Applications of a Defined Murine Microbial Community. ILAR J. 2015, 56, 169-178. [CrossRef]

21. Orcutt, R.; Gianni, F.; Judge, R. Development of an "altered Schaedler flora" for NCI gnotobiotic rodents. Microecol. Ther. 1987, 17, 59.

22. Dewhirst, F.E.; Chien, C.C.; Paster, B.J.; Ericson, R.L.; Orcutt, R.P.; Schauer, D.B.; Fox, J.G. Phylogeny of the defined murine microbiota: Altered Schaedler flora. Appl. Environ. Microbiol. 1999, 65, 3287-3292. [CrossRef]

23. Bolsega, S.; Basic, M.; Smoczek, A.; Buettner, M.; Eberl, C.; Ahrens, D.; Odum, K.A.; Stecher, B.; Bleich, A. Composition of the Intestinal Microbiota Determines the Outcome of Virus-Triggered Colitis in Mice. Front. Immunol. 2019, 10, 1708. [CrossRef] [PubMed]

24. Stecher, B.; Chaffron, S.; Kappeli, R.; Hapfelmeier, S.; Freedrich, S.; Weber, T.C.; Kirundi, J.; Suar, M.; McCoy, K.D.; von Mering, C.; et al. Like will to like: Abundances of closely related species can predict susceptibility to intestinal colonization by pathogenic and commensal bacteria. PLoS Pathog. 2010, 6, e1000711. [CrossRef] [PubMed]

25. Stehr, M.; Greweling, M.C.; Tischer, S.; Singh, M.; Blocker, H.; Monner, D.A.; Muller, W. Charles River altered Schaedler flora (CRASF) remained stable for four years in a mouse colony housed in individually ventilated cages. Lab. Anim. 2009, 43, 362-370. [CrossRef] [PubMed]

26. Basic, M.; Bolsega, S.; Smoczek, A.; Glasner, J.; Hiergeist, A.; Eberl, C.; Stecher, B.; Gessner, A.; Bleich, A. Monitoring and contamination incidence of gnotobiotic experiments performed in microisolator cages. Int. J. Med. Microbiol. 2021, $311,151482$. [CrossRef]

27. Elie, C.; Mathieu, A.; Saliou, A.; Villain, A.; Darnaud, M.; Leulier, F.; Tamellini, A. Draft Genome Sequences of 15 Bacterial Species Constituting the Stable Defined Intestinal Microbiota of the GM15 Gnotobiotic Mouse Model. Microbiol. Resour. Announc. 2020, 9 , e00686-20. [CrossRef] 
28. Li, H.; Limenitakis, J.P.; Fuhrer, T.; Geuking, M.B.; Lawson, M.A.; Wyss, M.; Brugiroux, S.; Keller, I.; Macpherson, J.A.; Rupp, S.; et al. The outer mucus layer hosts a distinct intestinal microbial niche. Nat. Commun. 2015, 6, 8292. [CrossRef]

29. Brugiroux, S.; Beutler, M.; Pfann, C.; Garzetti, D.; Ruscheweyh, H.J.; Ring, D.; Diehl, M.; Herp, S.; Lotscher, Y.; Hussain, S.; et al. Genome-guided design of a defined mouse microbiota that confers colonization resistance against Salmonella enterica serovar Typhimurium. Nat. Microbiol. 2016, 2, 16215. [CrossRef]

30. Eberl, C.; Ring, D.; Munch, P.C.; Beutler, M.; Basic, M.; Slack, E.C.; Schwarzer, M.; Srutkova, D.; Lange, A.; Frick, J.S.; et al. Reproducible Colonization of Germ-Free Mice with the Oligo-Mouse-Microbiota in Different Animal Facilities. Front. Microbiol. 2019, 10, 2999. [CrossRef] [PubMed]

31. Streidl, T.; Karkossa, I.; Segura Munoz, R.R.; Eberl, C.; Zaufel, A.; Plagge, J.; Schmaltz, R.; Schubert, K.; Basic, M.; Schneider, K.M.; et al. The gut bacterium Extibacter muris produces secondary bile acids and influences liver physiology in gnotobiotic mice. Gut Microbes 2021, 13, 1-21. [CrossRef] [PubMed]

32. Eftychi, C.; Schwarzer, R.; Vlantis, K.; Wachsmuth, L.; Basic, M.; Wagle, P.; Neurath, M.F.; Becker, C.; Bleich, A.; Pasparakis, M. Temporally Distinct Functions of the Cytokines IL-12 and IL-23 Drive Chronic Colon Inflammation in Response to Intestinal Barrier Impairment. Immunity 2019, 51, 367-380.e364. [CrossRef] [PubMed]

33. Kittana, H.; Gomes-Neto, J.C.; Heck, K.; Geis, A.L.; Segura Munoz, R.R.; Cody, L.A.; Schmaltz, R.J.; Bindels, L.B.; Sinha, R.; Hostetter, J.M.; et al. Commensal Escherichia coli Strains Can Promote Intestinal Inflammation via Differential Interleukin-6 Production. Front. Immunol. 2018, 9, 2318. [CrossRef] [PubMed]

34. Basic, M.; Keubler, L.M.; Buettner, M.; Achard, M.; Breves, G.; Schroder, B.; Smoczek, A.; Jorns, A.; Wedekind, D.; Zschemisch, N.H.; et al. Norovirus triggered microbiota-driven mucosal inflammation in interleukin 10-deficient mice. Inflamm. Bowel Dis. 2014, 20, 431-443. [CrossRef]

35. Donohoe, D.R.; Holley, D.; Collins, L.B.; Montgomery, S.A.; Whitmore, A.C.; Hillhouse, A.; Curry, K.P.; Renner, S.W.; Greenwalt, A.; Ryan, E.P.; et al. A gnotobiotic mouse model demonstrates that dietary fiber protects against colorectal tumorigenesis in a microbiota- and butyrate-dependent manner. Cancer Discov. 2014, 4, 1387-1397. [CrossRef]

36. Studer, N.; Desharnais, L.; Beutler, M.; Brugiroux, S.; Terrazos, M.A.; Menin, L.; Schurch, C.M.; McCoy, K.D.; Kuehne, S.A.; Minton, N.P.; et al. Functional Intestinal Bile Acid 7alpha-Dehydroxylation by Clostridium scindens Associated with Protection from Clostridium difficile Infection in a Gnotobiotic Mouse Model. Front. Cell Infect. Microbiol. 2016, 6, 191. [CrossRef]

37. Fischer, F.; Romero, R.; Hellhund, A.; Linne, U.; Bertrams, W.; Pinkenburg, O.; Eldin, H.S.; Binder, K.; Jacob, R.; Walker, A.; et al. Dietary cellulose induces anti-inflammatory immunity and transcriptional programs via maturation of the intestinal microbiota. Gut Microbes 2020, 12, 1-17. [CrossRef]

38. Herp, S.; Brugiroux, S.; Garzetti, D.; Ring, D.; Jochum, L.M.; Beutler, M.; Eberl, C.; Hussain, S.; Walter, S.; Gerlach, R.G.; et al. Mucispirillum schaedleri Antagonizes Salmonella Virulence to Protect Mice against Colitis. Cell Host Microbe 2019, 25, 681-694.e688. [CrossRef]

39. Goodman, A.L.; Kallstrom, G.; Faith, J.J.; Reyes, A.; Moore, A.; Dantas, G.; Gordon, J.I. Extensive personal human gut microbiota culture collections characterized and manipulated in gnotobiotic mice. Proc. Natl. Acad. Sci. USA 2011, 108, 6252-6257. [CrossRef]

40. Becker, N.; Kunath, J.; Loh, G.; Blaut, M. Human intestinal microbiota: Characterization of a simplified and stable gnotobiotic rat model. Gut Microbes 2011, 2, 25-33. [CrossRef]

41. Kovatcheva-Datchary, P.; Shoaie, S.; Lee, S.; Wahlstrom, A.; Nookaew, I.; Hallen, A.; Perkins, R.; Nielsen, J.; Backhed, F. Simplified Intestinal Microbiota to Study Microbe-Diet-Host Interactions in a Mouse Model. Cell Rep. 2019, 26, 3772-3783.e3776. [CrossRef]

42. Rezzonico, E.; Mestdagh, R.; Delley, M.; Combremont, S.; Dumas, M.E.; Holmes, E.; Nicholson, J.; Bibiloni, R. Bacterial adaptation to the gut environment favors successful colonization: Microbial and metabonomic characterization of a simplified microbiota mouse model. Gut Microbes 2011, 2, 307-318. [CrossRef] [PubMed]

43. McNulty, N.P.; Yatsunenko, T.; Hsiao, A.; Faith, J.J.; Muegge, B.D.; Goodman, A.L.; Henrissat, B.; Oozeer, R.; Cools-Portier, S.; Gobert, G.; et al. The impact of a consortium of fermented milk strains on the gut microbiome of gnotobiotic mice and monozygotic twins. Sci. Transl. Med. 2011, 3, 106ra106. [CrossRef]

44. Mark Welch, J.L.; Hasegawa, Y.; McNulty, N.P.; Gordon, J.I.; Borisy, G.G. Spatial organization of a model 15-member human gut microbiota established in gnotobiotic mice. Proc. Natl. Acad. Sci. USA 2017, 114, E9105-E9114. [CrossRef] [PubMed]

45. Denou, E.; Rezzonico, E.; Panoff, J.M.; Arigoni, F.; Brussow, H. A Mesocosm of Lactobacillus johnsonii, Bifidobacterium longum, and Escherichia coli in the mouse gut. DNA Cell Biol. 2009, 28, 413-422. [CrossRef]

46. Rakoff-Nahoum, S.; Foster, K.R.; Comstock, L.E. The evolution of cooperation within the gut microbiota. Nature 2016, 533, 255-259. [CrossRef] [PubMed]

47. Ng, K.M.; Ferreyra, J.A.; Higginbottom, S.K.; Lynch, J.B.; Kashyap, P.C.; Gopinath, S.; Naidu, N.; Choudhury, B.; Weimer, B.C.; Monack, D.M.; et al. Microbiota-liberated host sugars facilitate post-antibiotic expansion of enteric pathogens. Nature 2013, 502, 96-99. [CrossRef]

48. Woting, A.; Pfeiffer, N.; Loh, G.; Klaus, S.; Blaut, M. Clostridium ramosum promotes high-fat diet-induced obesity in gnotobiotic mouse models. mBio 2014, 5, e01530-14. [CrossRef] [PubMed]

49. Weitkunat, K.; Schumann, S.; Petzke, K.J.; Blaut, M.; Loh, G.; Klaus, S. Effects of dietary inulin on bacterial growth, short-chain fatty acid production and hepatic lipid metabolism in gnotobiotic mice. J. Nutr. Biochem. 2015, 26, 929-937. [CrossRef] 
50. Ring, C.; Klopfleisch, R.; Dahlke, K.; Basic, M.; Bleich, A.; Blaut, M. Akkermansia muciniphila strain ATCC BAA-835 does not promote short-term intestinal inflammation in gnotobiotic interleukin-10-deficient mice. Gut Microbes 2019, 10, 188-203. [CrossRef]

51. Ganesh, B.P.; Klopfleisch, R.; Loh, G.; Blaut, M. Commensal Akkermansia muciniphila exacerbates gut inflammation in Salmonella Typhimurium-infected gnotobiotic mice. PLOS ONE 2013, 8, e74963. [CrossRef]

52. Eun, C.S.; Mishima, Y.; Wohlgemuth, S.; Liu, B.; Bower, M.; Carroll, I.M.; Sartor, R.B. Induction of bacterial antigen-specific colitis by a simplified human microbiota consortium in gnotobiotic interleukin-10-/- mice. Infect. Immun. 2014, 82, 2239-2246. [CrossRef] [PubMed]

53. Lengfelder, I.; Sava, I.G.; Hansen, J.J.; Kleigrewe, K.; Herzog, J.; Neuhaus, K.; Hofmann, T.; Sartor, R.B.; Haller, D. Complex Bacterial Consortia Reprogram the Colitogenic Activity of Enterococcus faecalis in a Gnotobiotic Mouse Model of Chronic, Immune-Mediated Colitis. Front. Immunol. 2019, 10, 1420. [CrossRef]

54. Martz, S.L.; McDonald, J.A.; Sun, J.; Zhang, Y.G.; Gloor, G.B.; Noordhof, C.; He, S.M.; Gerbaba, T.K.; Blennerhassett, M.; Hurlbut, D.J.; et al. Administration of defined microbiota is protective in a murine Salmonella infection model. Sci. Rep. 2015, 5, 16094. [CrossRef]

55. Luk, B.; Veeraragavan, S.; Engevik, M.; Balderas, M.; Major, A.; Runge, J.; Luna, R.A.; Versalovic, J. Postnatal colonization with human "infant-type" Bifidobacterium species alters behavior of adult gnotobiotic mice. PLoS ONE 2018, 13, e0196510. [CrossRef]

56. Crost, E.H.; Pujol, A.; Ladire, M.; Dabard, J.; Raibaud, P.; Carlier, J.P.; Fons, M. Production of an antibacterial substance in the digestive tract involved in colonization-resistance against Clostridium perfringens. Anaerobe 2010, 16, 597-603. [CrossRef]

57. Atarashi, K.; Tanoue, T.; Shima, T.; Imaoka, A.; Kuwahara, T.; Momose, Y.; Cheng, G.; Yamasaki, S.; Saito, T.; Ohba, Y.; et al. Induction of colonic regulatory T cells by indigenous Clostridium species. Science 2011, 331, 337-341. [CrossRef] [PubMed]

58. McNulty, N.P.; Wu, M.; Erickson, A.R.; Pan, C.; Erickson, B.K.; Martens, E.C.; Pudlo, N.A.; Muegge, B.D.; Henrissat, B.; Hettich, R.L.; et al. Effects of diet on resource utilization by a model human gut microbiota containing Bacteroides cellulosilyticus WH2, a symbiont with an extensive glycobiome. PLoS Biol. 2013, 11, e1001637. [CrossRef]

59. Rey, F.E.; Gonzalez, M.D.; Cheng, J.; Wu, M.; Ahern, P.P.; Gordon, J.I. Metabolic niche of a prominent sulfate-reducing human gut bacterium. Proc. Natl. Acad. Sci. USA 2013, 110, 13582-13587. [CrossRef]

60. Faith, J.J.; McNulty, N.P.; Rey, F.E.; Gordon, J.I. Predicting a human gut microbiota's response to diet in gnotobiotic mice. Science 2011, 333, 101-104. [CrossRef]

61. Narushima, S.; Itoha, K.; Miyamoto, Y.; Park, S.H.; Nagata, K.; Kuruma, K.; Uchida, K. Deoxycholic acid formation in gnotobiotic mice associated with human intestinal bacteria. Lipids 2006, 41, 835-843. [CrossRef]

62. Ridlon, J.M.; Devendran, S.; Alves, J.M.; Doden, H.; Wolf, P.G.; Pereira, G.V.; Ly, L.; Volland, A.; Takei, H.; Nittono, H.; et al. The 'in vivo lifestyle' of bile acid 7alpha-dehydroxylating bacteria: Comparative genomics, metatranscriptomic, and bile acid metabolomics analysis of a defined microbial community in gnotobiotic mice. Gut Microbes 2020, 11, 381-404. [CrossRef] [PubMed]

63. Yatsunenko, T.; Rey, F.E.; Manary, M.J.; Trehan, I.; Dominguez-Bello, M.G.; Contreras, M.; Magris, M.; Hidalgo, G.; Baldassano, R.N.; Anokhin, A.P.; et al. Human gut microbiome viewed across age and geography. Nature 2012, 486, 222-227. [CrossRef] [PubMed]

64. Chu, D.M.; Ma, J.; Prince, A.L.; Antony, K.M.; Seferovic, M.D.; Aagaard, K.M. Maturation of the infant microbiome community structure and function across multiple body sites and in relation to mode of delivery. Nat. Med. 2017, 23, 314-326. [CrossRef]

65. Palmer, C.; Bik, E.M.; DiGiulio, D.B.; Relman, D.A.; Brown, P.O. Development of the human infant intestinal microbiota. PLoS Biol. 2007, 5, e177. [CrossRef]

66. Arentsen, T.; Qian, Y.; Gkotzis, S.; Femenia, T.; Wang, T.; Udekwu, K.; Forssberg, H.; Diaz Heijtz, R. The bacterial peptidoglycansensing molecule Pglyrp2 modulates brain development and behavior. Mol. Psychiatry 2017, 22, 257-266. [CrossRef]

67. Lupp, C.; Robertson, M.L.; Wickham, M.E.; Sekirov, I.; Champion, O.L.; Gaynor, E.C.; Finlay, B.B. Host-mediated inflammation disrupts the intestinal microbiota and promotes the overgrowth of Enterobacteriaceae. Cell Host Microbe 2007, 2, 204. [CrossRef] [PubMed]

68. Stecher, B.; Robbiani, R.; Walker, A.W.; Westendorf, A.M.; Barthel, M.; Kremer, M.; Chaffron, S.; Macpherson, A.J.; Buer, J.; Parkhill, J.; et al. Salmonella enterica serovar typhimurium exploits inflammation to compete with the intestinal microbiota. PLoS Biol. 2007, 5, 2177-2189. [CrossRef]

69. Rohr, J.R.; Barrett, C.B.; Civitello, D.J.; Craft, M.E.; Delius, B.; DeLeo, G.A.; Hudson, P.J.; Jouanard, N.; Nguyen, K.H.; Ostfeld, R.S.; et al. Emerging human infectious diseases and the links to global food production. Nat. Sustain. 2019, 2, 445-456. [CrossRef]

70. Dethlefsen, L.; Huse, S.; Sogin, M.L.; Relman, D.A. The pervasive effects of an antibiotic on the human gut microbiota, as revealed by deep 16S rRNA sequencing. PLoS Biol. 2008, 6, e280. [CrossRef]

71. Chang, J.Y.; Antonopoulos, D.A.; Kalra, A.; Tonelli, A.; Khalife, W.T.; Schmidt, T.M.; Young, V.B. Decreased diversity of the fecal Microbiome in recurrent Clostridium difficile-associated diarrhea. J. Infect. Dis. 2008, 197, 435-438. [CrossRef]

72. Kang, J.D.; Myers, C.J.; Harris, S.C.; Kakiyama, G.; Lee, I.K.; Yun, B.S.; Matsuzaki, K.; Furukawa, M.; Min, H.K.; Bajaj, J.S.; et al. Bile Acid 7alpha-Dehydroxylating Gut Bacteria Secrete Antibiotics that Inhibit Clostridium difficile: Role of Secondary Bile Acids. Cell Chem. Biol. 2019, 26, 27-34.e24. [CrossRef] 
73. Narushima, S.; Itoh, K.; Takamine, F.; Uchida, K. Absence of cecal secondary bile acids in gnotobiotic mice associated with two human intestinal bacteria with the ability to dehydroxylate bile acids in vitro. Microbiol. Immunol. 1999, 43, 893-897. [CrossRef] [PubMed]

74. Derrien, M.; Belzer, C.; de Vos, W.M. Akkermansia muciniphila and its role in regulating host functions. Microb. Pathog. 2017, 106, 171-181. [CrossRef] [PubMed]

75. Keubler, L.M.; Buettner, M.; Hager, C.; Bleich, A. A Multihit Model: Colitis Lessons from the Interleukin-10-deficient Mouse. Inflamm. Bowel Dis. 2015, 21, 1967-1975. [CrossRef]

76. Sellon, R.K.; Tonkonogy, S.; Schultz, M.; Dieleman, L.A.; Grenther, W.; Balish, E.; Rennick, D.M.; Sartor, R.B. Resident enteric bacteria are necessary for development of spontaneous colitis and immune system activation in interleukin-10-deficient mice. Infect. Immun. 1998, 66, 5224-5231. [CrossRef]

77. Schaubeck, M.; Clavel, T.; Calasan, J.; Lagkouvardos, I.; Haange, S.B.; Jehmlich, N.; Basic, M.; Dupont, A.; Hornef, M.; von Bergen, M.; et al. Dysbiotic gut microbiota causes transmissible Crohn's disease-like ileitis independent of failure in antimicrobial defence. Gut 2016, 65, 225-237. [CrossRef]

78. Stolzer, I.; Kaden-Volynets, V.; Ruder, B.; Letizia, M.; Bittel, M.; Rausch, P.; Basic, M.; Bleich, A.; Baines, J.F.; Neurath, M.F.; et al. Environmental Microbial Factors Determine the Pattern of Inflammatory Lesions in a Murine Model of Crohn's Disease-Like Inflammation. Inflamm. Bowel Dis. 2020, 26, 66-79. [CrossRef]

79. Kang, C.S.; Ban, M.; Choi, E.J.; Moon, H.G.; Jeon, J.S.; Kim, D.K.; Park, S.K.; Jeon, S.G.; Roh, T.Y.; Myung, S.J.; et al. Extracellular vesicles derived from gut microbiota, especially Akkermansia muciniphila, protect the progression of dextran sulfate sodiuminduced colitis. PLoS ONE 2013, 8, e76520. [CrossRef] [PubMed]

80. Png, C.W.; Linden, S.K.; Gilshenan, K.S.; Zoetendal, E.G.; McSweeney, C.S.; Sly, L.I.; McGuckin, M.A.; Florin, T.H. Mucolytic bacteria with increased prevalence in IBD mucosa augment in vitro utilization of mucin by other bacteria. Am. J. Gastroenterol. 2010, 105, 2420-2428. [CrossRef]

81. Everard, A.; Belzer, C.; Geurts, L.; Ouwerkerk, J.P.; Druart, C.; Bindels, L.B.; Guiot, Y.; Derrien, M.; Muccioli, G.G.; Delzenne, N.M.; et al. Cross-talk between Akkermansia muciniphila and intestinal epithelium controls diet-induced obesity. Proc. Natl. Acad. Sci. USA 2013, 110, 9066-9071. [CrossRef] [PubMed]

82. Plovier, H.; Everard, A.; Druart, C.; Depommier, C.; Van Hul, M.; Geurts, L.; Chilloux, J.; Ottman, N.; Duparc, T.; Lichtenstein, L.; et al. A purified membrane protein from Akkermansia muciniphila or the pasteurized bacterium improves metabolism in obese and diabetic mice. Nat. Med. 2017, 23, 107-113. [CrossRef] [PubMed]

83. Depommier, C.; Van Hul, M.; Everard, A.; Delzenne, N.M.; De Vos, W.M.; Cani, P.D. Pasteurized Akkermansia muciniphila increases whole-body energy expenditure and fecal energy excretion in diet-induced obese mice. Gut Microbes 2020, 11, 1231-1245. [CrossRef] [PubMed]

84. Cadwell, K.; Patel, K.K.; Maloney, N.S.; Liu, T.C.; Ng, A.C.; Storer, C.E.; Head, R.D.; Xavier, R.; Stappenbeck, T.S.; Virgin, H.W. Virus-plus-susceptibility gene interaction determines Crohn's disease gene Atg16L1 phenotypes in intestine. Cell 2010, 141, 1135-1145. [CrossRef]

85. Khan, R.R.; Lawson, A.D.; Minnich, L.L.; Martin, K.; Nasir, A.; Emmett, M.K.; Welch, C.A.; Udall, J.N., Jr. Gastrointestinal norovirus infection associated with exacerbation of inflammatory bowel disease. J. Pediatr. Gastroenterol. Nutr. 2009, 48, 328-333. [CrossRef] [PubMed]

86. Lencioni, K.C.; Seamons, A.; Treuting, P.M.; Maggio-Price, L.; Brabb, T. Murine norovirus: An intercurrent variable in a mouse model of bacteria-induced inflammatory bowel disease. Comp. Med. 2008, 58, 522-533.

87. Zeissig, S.; Bürgel, N.; Günzel, D.; Richter, J.; Mankertz, J.; Wahnschaffe, U.; Kroesen, A.J.; Zeitz, M.; Fromm, M.; Schulzke, J.D. Changes in expression and distribution of claudin 2, 5 and 8 lead to discontinuous tight junctions and barrier dysfunction in active Crohn's disease. Gut 2007, 56, 61-72. [CrossRef] [PubMed]

88. Wyatt, J.; Vogelsang, H.; Hubl, W.; Waldhoer, T.; Lochs, H. Intestinal permeability and the prediction of relapse in Crohn's disease. Lancet 1993, 341, 1437-1439. [CrossRef]

89. Atarashi, K.; Tanoue, T.; Oshima, K.; Suda, W.; Nagano, Y.; Nishikawa, H.; Fukuda, S.; Saito, T.; Narushima, S.; Hase, K.; et al. Treg induction by a rationally selected mixture of Clostridia strains from the human microbiota. Nature 2013, 500, 232-236. [CrossRef]

90. Tedelind, S.; Westberg, F.; Kjerrulf, M.; Vidal, A. Anti-inflammatory properties of the short-chain fatty acids acetate and propionate: A study with relevance to inflammatory bowel disease. World J. Gastroenterol. WJG 2007, 13, 2826-2832. [CrossRef]

91. Hill, D.A.; Hoffmann, C.; Abt, M.C.; Du, Y.; Kobuley, D.; Kirn, T.J.; Bushman, F.D.; Artis, D. Metagenomic analyses reveal antibiotic-induced temporal and spatial changes in intestinal microbiota with associated alterations in immune cell homeostasis. Mucosal Immunol. 2010, 3, 148-158. [CrossRef]

92. Dethlefsen, L.; Relman, D.A. Incomplete recovery and individualized responses of the human distal gut microbiota to repeated antibiotic perturbation. Proc. Natl. Acad. Sci. USA 2011, 108 (Suppl. 1), 4554-4561. [CrossRef]

93. Devkota, S.; Wang, Y.; Musch, M.; Leone, V.; Fehlner-Peach, H.; Nadimpalli, A.; Antonopoulos, D.A.; Jabri, B.; Chang, E.B. Dietary fat-induced taurocholic acid production promotes pathobiont and colitis in IL-10(-/ - ) mice. Nature 2012, 487, 104-108. [CrossRef] [PubMed]

94. Llewellyn, S.R.; Britton, G.J.; Contijoch, E.J.; Vennaro, O.H.; Mortha, A.; Colombel, J.F.; Grinspan, A.; Clemente, J.C.; Merad, M.; Faith, J.J. Interactions Between Diet and the Intestinal Microbiota Alter Intestinal Permeability and Colitis Severity in Mice. Gastroenterology 2018, 154, 1037-1046.e1032. [CrossRef] 
95. Daniel, H.; Gholami, A.M.; Berry, D.; Desmarchelier, C.; Hahne, H.; Loh, G.; Mondot, S.; Lepage, P.; Rothballer, M.; Walker, A.; et al. High-fat diet alters gut microbiota physiology in mice. ISME J. 2014, 8, 295-308. [CrossRef]

96. Wu, G.D.; Chen, J.; Hoffmann, C.; Bittinger, K.; Chen, Y.Y.; Keilbaugh, S.A.; Bewtra, M.; Knights, D.; Walters, W.A.; Knight, R.; et al. Linking long-term dietary patterns with gut microbial enterotypes. Science 2011, 334, 105-108. [CrossRef] [PubMed]

97. Walker, A.W.; Ince, J.; Duncan, S.H.; Webster, L.M.; Holtrop, G.; Ze, X.; Brown, D.; Stares, M.D.; Scott, P.; Bergerat, A.; et al. Dominant and diet-responsive groups of bacteria within the human colonic microbiota. ISME J. 2011, 5, 220-230. [CrossRef] [PubMed]

98. Turnbaugh, P.J.; Ley, R.E.; Mahowald, M.A.; Magrini, V.; Mardis, E.R.; Gordon, J.I. An obesity-associated gut microbiome with increased capacity for energy harvest. Nature 2006, 444, 1027-1031. [CrossRef] [PubMed]

99. Cani, P.D.; Knauf, C.; Iglesias, M.A.; Drucker, D.J.; Delzenne, N.M.; Burcelin, R. Improvement of glucose tolerance and hepatic insulin sensitivity by oligofructose requires a functional glucagon-like peptide 1 receptor. Diabetes 2006, 55, 1484-1490. [CrossRef]

100. Cani, P.D.; Neyrinck, A.M.; Fava, F.; Knauf, C.; Burcelin, R.G.; Tuohy, K.M.; Gibson, G.R.; Delzenne, N.M. Selective increases of bifidobacteria in gut microflora improve high-fat-diet-induced diabetes in mice through a mechanism associated with endotoxaemia. Diabetologia 2007, 50, 2374-2383. [CrossRef]

101. Woting, A.; Pfeiffer, N.; Hanske, L.; Loh, G.; Klaus, S.; Blaut, M. Alleviation of high fat diet-induced obesity by oligofructose in gnotobiotic mice is independent of presence of Bifidobacterium longum. Mol. Nutr. Food Res. 2015, 59, 2267-2278. [CrossRef]

102. Rahat-Rozenbloom, S.; Fernandes, J.; Gloor, G.B.; Wolever, T.M. Evidence for greater production of colonic short-chain fatty acids in overweight than lean humans. Int. J. Obes. 2014, 38, 1525-1531. [CrossRef]

103. Isken, F.; Klaus, S.; Osterhoff, M.; Pfeiffer, A.F.; Weickert, M.O. Effects of long-term soluble vs. insoluble dietary fiber intake on high-fat diet-induced obesity in C57BL/6J mice. J. Nutr. Biochem. 2010, 21, 278-284. [CrossRef]

104. Buffie, C.G.; Bucci, V.; Stein, R.R.; McKenney, P.T.; Ling, L.; Gobourne, A.; No, D.; Liu, H.; Kinnebrew, M.; Viale, A.; et al. Precision microbiome reconstitution restores bile acid mediated resistance to Clostridium difficile. Nature 2015, 517, 205-208. [CrossRef] [PubMed]

105. Duboc, H.; Rajca, S.; Rainteau, D.; Benarous, D.; Maubert, M.A.; Quervain, E.; Thomas, G.; Barbu, V.; Humbert, L.; Despras, G.; et al. Connecting dysbiosis, bile-acid dysmetabolism and gut inflammation in inflammatory bowel diseases. Gut 2013, 62, 531-539. [CrossRef] [PubMed]

106. Keren, N.; Konikoff, F.M.; Paitan, Y.; Gabay, G.; Reshef, L.; Naftali, T.; Gophna, U. Interactions between the intestinal microbiota and bile acids in gallstones patients. Environ. Microbiol. Rep. 2015, 7, 874-880. [CrossRef] [PubMed]

107. Baxter, N.T.; Zackular, J.P.; Chen, G.Y.; Schloss, P.D. Structure of the gut microbiome following colonization with human feces determines colonic tumor burden. Microbiome 2014, 2, 20. [CrossRef]

108. Wong, S.H.; Zhao, L.; Zhang, X.; Nakatsu, G.; Han, J.; Xu, W.; Xiao, X.; Kwong, T.N.Y.; Tsoi, H.; Wu, W.K.K.; et al. Gavage of Fecal Samples From Patients With Colorectal Cancer Promotes Intestinal Carcinogenesis in Germ-Free and Conventional Mice. Gastroenterology 2017, 153, 1621-1633.e1626. [CrossRef]

109. Li, L.; Li, X.; Zhong, W.; Yang, M.; Xu, M.; Sun, Y.; Ma, J.; Liu, T.; Song, X.; Dong, W.; et al. Gut microbiota from colorectal cancer patients enhances the progression of intestinal adenoma in Apc(min/+) mice. EBioMedicine 2019, 48, 301-315. [CrossRef]

110. Tomkovich, S.; Yang, Y.; Winglee, K.; Gauthier, J.; Muhlbauer, M.; Sun, X.; Mohamadzadeh, M.; Liu, X.; Martin, P.; Wang, G.P.; et al. Locoregional Effects of Microbiota in a Preclinical Model of Colon Carcinogenesis. Cancer Res. 2017, 77, 2620-2632. [CrossRef]

111. Sui, H.; Zhang, L.; Gu, K.; Chai, N.; Ji, Q.; Zhou, L.; Wang, Y.; Ren, J.; Yang, L.; Zhang, B.; et al. YYFZBJS ameliorates colorectal cancer progression in Apc(Min/+) mice by remodeling gut microbiota and inhibiting regulatory T-cell generation. Cell Commun. Signal. 2020, 18, 113. [CrossRef] [PubMed]

112. Tomkovich, S.; Gharaibeh, R.Z.; Dejea, C.M.; Pope, J.L.; Jiang, J.; Winglee, K.; Gauthier, J.; Newsome, R.C.; Yang, Y.; Fodor, A.A.; et al. Human Colon Mucosal Biofilms and Murine Host Communicate via Altered mRNA and microRNA Expression during Cancer. MSystems 2020, 5, e00451-19. [CrossRef] [PubMed]

113. Krych, L.; Hansen, C.H.; Hansen, A.K.; van den Berg, F.W.; Nielsen, D.S. Quantitatively different, yet qualitatively alike: A meta-analysis of the mouse core gut microbiome with a view towards the human gut microbiome. PLoS ONE 2013, 8, e62578. [CrossRef]

114. Ley, R.E.; Turnbaugh, P.J.; Klein, S.; Gordon, J.I. Microbial ecology: Human gut microbes associated with obesity. Nature 2006, 444, 1022-1023. [CrossRef] [PubMed]

115. Jeffery, I.B.; O’Toole, P.W.; Ohman, L.; Claesson, M.J.; Deane, J.; Quigley, E.M.; Simren, M. An irritable bowel syndrome subtype defined by species-specific alterations in faecal microbiota. Gut 2012, 61, 997-1006. [CrossRef]

116. Nagpal, R.; Wang, S.; Solberg Woods, L.C.; Seshie, O.; Chung, S.T.; Shively, C.A.; Register, T.C.; Craft, S.; McClain, D.A.; Yadav, H. Comparative Microbiome Signatures and Short-Chain Fatty Acids in Mouse, Rat, Non-human Primate, and Human Feces. Front. Microbiol. 2018, 9, 2897. [CrossRef]

117. Chung, H.; Pamp, S.J.; Hill, J.A.; Surana, N.K.; Edelman, S.M.; Troy, E.B.; Reading, N.C.; Villablanca, E.J.; Wang, S.; Mora, J.R.; et al. Gut immune maturation depends on colonization with a host-specific microbiota. Cell 2012, 149, 1578-1593. [CrossRef] [PubMed]

118. Wos-Oxley, M.; Bleich, A.; Oxley, A.P.; Kahl, S.; Janus, L.M.; Smoczek, A.; Nahrstedt, H.; Pils, M.C.; Taudien, S.; Platzer, M.; et al. Comparative evaluation of establishing a human gut microbial community within rodent models. Gut Microbes 2012, 3, $234-249$. [CrossRef] [PubMed] 
119. Sayin, S.I.; Wahlstrom, A.; Felin, J.; Jantti, S.; Marschall, H.U.; Bamberg, K.; Angelin, B.; Hyotylainen, T.; Oresic, M.; Backhed, F. Gut microbiota regulates bile acid metabolism by reducing the levels of tauro-beta-muricholic acid, a naturally occurring FXR antagonist. Cell Metab. 2013, 17, 225-235. [CrossRef]

120. Seedorf, H.; Griffin, N.W.; Ridaura, V.K.; Reyes, A.; Cheng, J.; Rey, F.E.; Smith, M.I.; Simon, G.M.; Scheffrahn, R.H.; Woebken, D.; et al. Bacteria from diverse habitats colonize and compete in the mouse gut. Cell 2014, 159, 253-266. [CrossRef]

121. Marcobal, A.; Kashyap, P.C.; Nelson, T.A.; Aronov, P.A.; Donia, M.S.; Spormann, A.; Fischbach, M.A.; Sonnenburg, J.L. A metabolomic view of how the human gut microbiota impacts the host metabolome using humanized and gnotobiotic mice. ISME J. 2013, 7, 1933-1943. [CrossRef]

122. Frese, S.A.; Benson, A.K.; Tannock, G.W.; Loach, D.M.; Kim, J.; Zhang, M.; Oh, P.L.; Heng, N.C.; Patil, P.B.; Juge, N.; et al. The evolution of host specialization in the vertebrate gut symbiont Lactobacillus reuteri. PLoS Genet. 2011, 7, e1001314. [CrossRef] [PubMed]

123. Wang, J.; Kalyan, S.; Steck, N.; Turner, L.M.; Harr, B.; Kunzel, S.; Vallier, M.; Hasler, R.; Franke, A.; Oberg, H.H.; et al. Analysis of intestinal microbiota in hybrid house mice reveals evolutionary divergence in a vertebrate hologenome. Nat. Commun. 2015, 6, 6440. [CrossRef]

124. Gulati, A.S.; Shanahan, M.T.; Arthur, J.C.; Grossniklaus, E.; von Furstenberg, R.J.; Kreuk, L.; Henning, S.J.; Jobin, C.; Sartor, R.B. Mouse background strain profoundly influences Paneth cell function and intestinal microbial composition. PLoS ONE 2012, 7, e32403. [CrossRef] [PubMed]

125. Turnbaugh, P.J.; Ridaura, V.K.; Faith, J.J.; Rey, F.E.; Knight, R.; Gordon, J.I. The effect of diet on the human gut microbiome: A metagenomic analysis in humanized gnotobiotic mice. Sci. Transl. Med. 2009, 1, 6ra14. [CrossRef]

126. Nguyen, T.L.; Vieira-Silva, S.; Liston, A.; Raes, J. How informative is the mouse for human gut microbiota research? Dis. Model. Mech. 2015, 8, 1-16. [CrossRef]

127. Fisher, C.K.; Mehta, P. Identifying keystone species in the human gut microbiome from metagenomic timeseries using sparse linear regression. PLoS ONE 2014, 9, e102451. [CrossRef]

128. Park, J.C.; Im, S.H. Of men in mice: The development and application of a humanized gnotobiotic mouse model for microbiome therapeutics. Exp. Mol. Med. 2020, 52, 1383-1396. [CrossRef]

129. Lagkouvardos, I.; Overmann, J.; Clavel, T. Cultured microbes represent a substantial fraction of the human and mouse gut microbiota. Gut Microbes 2017, 8, 493-503. [CrossRef]

130. Browne, H.P.; Forster, S.C.; Anonye, B.O.; Kumar, N.; Neville, B.A.; Stares, M.D.; Goulding, D.; Lawley, T.D. Culturing of 'unculturable' human microbiota reveals novel taxa and extensive sporulation. Nature 2016, 533, 543-546. [CrossRef]

131. Sohngen, C.; Podstawka, A.; Bunk, B.; Gleim, D.; Vetcininova, A.; Reimer, L.C.; Ebeling, C.; Pendarovski, C.; Overmann, J. BacDive-The Bacterial Diversity Metadatabase in 2016. Nucleic Acids Res. 2016, 44, D581-D585. [CrossRef] [PubMed]

132. Chun, J.; Lee, J.H.; Jung, Y.; Kim, M.; Kim, S.; Kim, B.K.; Lim, Y.W. EzTaxon: A web-based tool for the identification of prokaryotes based on 16S ribosomal RNA gene sequences. Int. J. Syst. Evol. Microbiol. 2007, 57, 2259-2261. [CrossRef] [PubMed] 